\title{
Ethylene functions as a suppressor of volatile production in rice
}

Kadis Mujiono ${ }^{1,2}$, Tilisa Tohi $^{1}$, Islam S. Sobhy ${ }^{1,3, \#}$, Yuko Hojo ${ }^{1}$, Nhan Thanh Ho ${ }^{1,4}$, Tomonori Shinya ${ }^{1}$, Ivan Galis ${ }^{1 *}$

${ }^{1}$ Institute of Plant Science and Resources, Okayama University, Kurashiki 710-0046, Japan

${ }^{2}$ Faculty of Agriculture, Mulawarman University, Samarinda 75119, Indonesia

${ }^{3}$ Department of Plant Protection, Faculty of Agriculture, Suez Canal university, 41522 Ismailia, Egypt

${ }^{4}$ Cuu Long Delta Rice Research Institute, Can Tho, Vietnam

kadismujiono@yahoo.com; tilisamounga@gmail.com; i.sobhy@keele.ac.uk; y-hojo@okayamau.ac.jp; htnhan07@gmail.com; shinyat@okayama-u.ac.jp; igalis@okayama-u.ac.jp

\# Current address: School of Life Sciences, Huxley Building, Keele University, Keele, Staffordshire, ST5 5BG, UK

\section{*Corresponding author contact information}

Email: igalis@okayama-u.ac.jp

Tel: +81-(0)86-434-1235

Kadis Mujiono (Orcid ID: 0000-0002-0706-3149)

Islam S. Sobhy (Orcid ID: 0000-0003-4984-1823)

Tomonori Shinya (Orcid ID: 0000-0003-1837-138X)

Ivan Galis (Orcid ID: 0000-0001-9840-8845)

Highlight: We show that ethylene acts as a general suppressor of volatile organic compound (VOC) production in rice plants during development and stress responses, including water submergence, and maturation-associated decrease in rice volatile production. 


\section{Funding information}

Grants-in-Aid for Scientific Research (No. 24570026 and 16K08143 to I.G., No. 18K05558 to T.S). T.T. was supported by Pacific-LEADS program from JICA (Japan International Cooperation Agency).

\section{Author contributions}

$\mathrm{KM}$ - designed and conducted experiments, analyzed data; wrote paper; TT - conducted experiments, analyzed data; ISS - designed experiments, wrote paper; YH - conducted experiments, analyzed data; NTH - conducted experiments, analyzed data; TS - designed experiments, wrote paper; IG - designed and conducted experiments, wrote paper.

\section{Conflict of interest}

The authors declare no conflict of interest. 


\begin{abstract}
We examined the role of ethylene in the production of rice (Oryza sativa) volatile organic compounds (VOCs), which act as indirect defense signals against herbivores in tritrophic interactions. Rice plants were exposed to exogenous ethylene (1 ppm) after simulated herbivory which consisted of mechanical wounds supplemented with the oral secretions (WOS) from the generalist herbivore larvae, Mythimna loreyi. Ethylene treatment highly suppressed VOCs in WOS-treated rice leaves, which was further corroborated by the reduced transcript levels of major VOC biosynthesis genes in ethylene-treated rice. In contrast, the accumulation of jasmonates (JA), known to control the VOCs in higher plants, and transcript levels of primary JA response genes, including $O S M Y C 2$, were not largely affected by ethylene application. At the functional level, flooding that is known to promote internode elongation in the young rice via ethylene signaling, consistent with the negative role of ethylene, suppressed the accumulation of VOCs in water-submerged rice leaves. Furthermore, in the maturing stage rice that naturally produced less volatiles, VOCs could be rescued by the application of ethylene perception inhibitor, 1-methylcyclopropene (1-MCP). Our data suggest that ethylene acts as an endogenous suppressor of VOCs in rice that applies to both plant stress responses and development.
\end{abstract}

\title{
Keywords
}

Ethylene; defense; gene expression; herbivory; rice (Oryza sativa); volatile organic compounds (VOCs). 


\section{Introduction}

Autotrophic plants serve as a nutrition for other heterotrophic herbivorous organisms on the planet. As countermeasures against damage from the insect herbivores, plants evolved various reactions collectively known as defense responses (War et al., 2012; Bruce, 2015; War et al., 2018). Constitutive defense systems, that operate in plants regardless of herbivory incidence, include cuticles, thorns, spikes, and toxic/anti-nutritive metabolites that often accumulate in developmental fashion, effectively reducing herbivore feeding and damage in plants (Wu and Baldwin, 2010). In addition to constitutive defenses, induced defense responses are rapidly triggered by herbivory in most plant species, which further inhibits the herbivore consumption, growth, and survival in the host plants (Kessler and Baldwin, 2001).

Defense chemicals, both volatile and non-volatile in nature, accumulate in the plant cells, where they act as direct defenses, phytoanticipins and phytoalexins (Mithofer and Boland, 2012). In addition, a subset of defense metabolites, known as volatile organic compounds (VOCs), is released into external environment, acting as attractants of natural enemies intended for herbivores (Turlings and Tumlinson, 1992), danger signals for conspecifics, and alert molecules for other plants in the neighborhood (Karban et al., 2000; Erb, 2018). It has been reported that some volatiles can be directly absorbed by neighbors, modified, and used as direct defense compounds against herbivores (Sugimoto et al., 2014). A group of VOCs triggered by herbivory is generally known as herbivore-induced plant volatiles (HIPVs). HIPVs can be, depending on type, released from herbivore-attacked plants either rapidly, through wounds (green leaf volatiles, GLVs) or gradually, by yet unknown mechanisms (terpenes, phenylpropanoids, and benzenoids) (Dicke et al., 2009; War et al., 2011). In addition, HIPVs can be produced and released systemically, i.e. in/from undamaged plant tissues (Pare and Tumlison, 1999). Volatile synthesis and release, similar to accumulation of direct defense metabolites, is primarily triggered by herbivore feeding, oviposition, or herbivore movement on the plant, and it is often amplified by chemical cues present in herbivore oral secretions, oviposition fluids, honeydew, and frass (Hilker and Meiners, 2010; Maffei et al., 2012). The essence of plant volatiles is further underlined by their roles in attraction of pollinators and frugivores (Rodriguez et al., 2013; Schiestl, 2015), function as antioxidants (Brilli et al., 2019), and antimicrobial agents (Junker and Tholl, 2013). 
HIPV production is attributed to three main metabolic pathways, terpenoid, phenylpropanoid, and fatty acid metabolism (Pichersky and Gershenzon, 2002; Dudareva et al., 2006). More than 2000 volatile compounds released in response to herbivory have been identified from 900 plant families (War et al., 2011). Reflecting the high natural diversity of VOCs, a blend of volatiles, rather than a single compound, is typically released from the plant in response to herbivore attack (Arimura et al., 2009). Discharging of some VOCs is tightly regulated and restricted to specific time of the day, showing a diurnal emission pattern (Christensen et al., 2013; Zeng et al., 2017). Volatile emissions from young and mature plants can also differ significantly, with the younger plants at vegetative stage releasing more volatiles compared to their older counterparts, which happens both constitutively and after elicitation by herbivory (Kollner et al., 2004; Shiojiri and Karban, 2006; Rostas and Eggert, 2008; Hare et al., 2010).

Defense responses against herbivores, including VOCs, are orchestrated by a network of plant hormones (Verhage et al., 2010). Specifically, plant defenses against chewing herbivores and necrotrophic pathogens are controlled by jasmonic acid (JA), while piercing and sucking herbivores, and biotrophic pathogens are mainly controlled by salicylic acid (SA). Both signaling pathways are actively cross-linked with other hormones (van Loon et al., 2006; Verhage et al., 2010). Different hormones can act individually, synergistically, or antagonistically, depending on the combination of environmental factors. JA and its biologically active form, jasmonoyl-Lisoleucine (JA-Ile), derived through octadecanoid pathway, and subsequent activity of acyl acid amido synthase JAR1, accumulate within minutes after wounding and/or herbivory in plants (Koo and Howe, 2009). Perception of JA-Ile by COI1-JAZ co-receptor complex then activates transcription of defense genes (Wasternack and Hause, 2013), including those involved in VOC biosynthesis. Despite involvement of JA-Ile in control of VOCs, volatiles show complex patterns of emissions that presumes participation of other hormones in the regulatory circuits, such as ethylene (Voelckel et al., 2001; Huang et al., 2005; Mewis et al., 2005; Huffaker et al., 2013; Pierik et al., 2014; Rehrig et al., 2014; Broekgaarden et al., 2015; Paudel and Bede, 2015; Schuman et al., 2018). With regard to volatiles, ethylene is already well-known for its positive role in ripening and aroma control in climacteric fruits (Zhu et al., 2005; Schaffer et al., 2007; Mitalo et al., 2019). 
Ethylene is produced from 1-aminocyclopropane-1-carboxylic acid (ACC), a product of ACC synthase (ACS), by another enzyme known as ACC oxidase (ACO) (Booker and DeLong, 2015; Larsen, 2015). Besides disease resistance, and modulation of plant defense responses against pathogens (van Loon et al., 2006; Broekgaarden et al., 2015; Helliwell et al., 2016; Kusajima et al., 2018), ethylene is also known to be involved in plant-insect interactions that includes emissions of volatiles from herbivore-attacked plants. For example, application of exogenous ethylene enhanced the lima bean (Horiuchi et al., 2001) and Medicago truncatula (Arimura et al., 2008) JA-mediated volatile production. In corn (Zea mays) seedlings, volatile emissions triggered by feeding of beet armyworm caterpillars were suppressed by pretreatment of plants with the inhibitor of ethylene perception, 1-methylcyclopropene (1-MCP; Schmelz et al., 2003). As determined by highly sensitive photo-acoustic spectrometer, rapid ethylene burst occurred in wild tobacco (Nicotiana attenuata) leaves treated with simulated herbivory (von Dahl et al., 2007). A negative effect of ethylene on plant resistance has also been reported, such as the defect in ethylene signaling which increased resistance of Arabidopsis plants to generalist herbivore, Egyptian cotton worm (Spodoptera littoralis) (Stotz et al., 2000). Furthermore, ethylene perception was necessary for the interference with parasitoid attraction to Plutella xylostella infested Arabidopsis by simultaneous feeding of a phloem feeder, whitefly (Bemisia tabaci) and P. xylostella (Zhang et al., 2013). Thus, both positive and negative roles of ethylene should be considered when scrutinizing the mechanisms of volatile emissions in plant-insect interactions.

Among land plants, rice (Oryza sativa), one of the most important food crops in Asia, shows a rapid elongation response during water submergence (flooding). As this stress response is wellknown to be regulated by ethylene (Iwamoto et al., 2010; Kuroha et al., 2018), we hypothesized that crosstalk of ethylene with other stress-related pathways might be specifically tailored in rice. In particular, the interactions of herbivory and flooding has not been examined in rice, although the overproduction of HIPVs could potentially cause damage to rice cells disabled in the release of volatiles to atmosphere. As flooding is more likely to occur in smaller (younger) plants, ontogeny-specific regulation of VOC production could be predicted in rice, as shown in other plants (Kollner et al., 2004; Shiojiri and Karban, 2006; Rostas and Eggert, 2008; Hare et al., 2010). However, such mechanisms have never been examined in detail. In this study, we focused on crosstalk of ethylene with the ontogeny and jasmonate-controlled production of VOCs in rice, and examined developmental- and stress-triggered accumulations patterns of VOCs in rice 
leaves. By use of ethylene treated plants, and those impaired in ethylene perception by 1-MCP treatment, we showed that ethylene works as a multifunctional negative regulator of VOCs in rice plants.

\section{Materials and methods}

\section{Plant growth conditions}

Japonica rice Oryza sativa L. cv. Nipponbare was used in all experiments. Seeds were placed in germination trays with nutrient-rich soil pellets, Kumiai Ube Baido No.2 (MC Ferticom, Tokyo, Japan), and two weeks later, seedlings were transferred into individual plastic pots (125 mL) with sterilized field soil mixed with nutrient-rich pellets at 4:1 (v/v) ratio. Plants were maintained in $53 \mathrm{~cm}(\mathrm{~L}) \times 34 \mathrm{~cm}(\mathrm{~W}) \times 6 \mathrm{~cm}(\mathrm{H})$ plastic trays filled with water in the cultivation room under controlled growth conditions $\left(14 \mathrm{~h}\right.$ photoperiod, temperature $\left.28 \pm 3^{\circ} \mathrm{C}\right)$. Germinations were repeated every week to generate series of plants at developmental age. In most experiments, youngest developed leaves of 6-10 week-old plants were used for treatments.

\section{Plant treatments}

Wounding and oral secretions (WOS). WOS (simulated herbivory) treatments were performed by making mechanical wounds, using a fabric pattern wheel, along both sides of the midvein of the youngest fully developed leaf on the plants, followed by application of $20 \mu \mathrm{L}$ water-diluted 3:1 (v/v) oral secretions (OS), evenly spread over the wounded leaf surface. OS were collected from Mythimna loreyi (MYL) (Lepidoptera: Noctuidae) as described in Shinya et al. (2016).

Ethylene treatment. To elucidate the role of ethylene in VOC biosynthesis, plants at five different growth stages (6-10 week after sowing) were treated with WOS, and each plant was immediately covered with transparent acrylic cylinder $(10 \mathrm{~cm}$ diameter, $60 \mathrm{~cm}$ height, volume $=$ $5 \mathrm{~L})$. Cylinders with plants were placed in small trays and system was sealed with water at the base. Ethylene standard gas (GL Sciences Inc., Japan) was injected into each cylinder to reach 1 ppm concentration of ethylene. Cylinders without ethylene were used as controls. Four hours later, leaves for volatile measurements were cut, weighed and inserted into clean $16 \mathrm{~cm}$ glass tubes enclosed with lid. Samples for internal leaf volatile analyses were stored at $-80{ }^{\circ} \mathrm{C}$. For hormone and gene expression, leaves were collected directly in $2 \mathrm{~mL}$ plastic screw-cup tubes before, and $0.5,1$, and $4 \mathrm{~h}$ after treatment, frozen in liquid nitrogen, and stored at $-80^{\circ} \mathrm{C}$. 
Ethylene treatment for elongation test. To determine the effect of ethylene on rice elongation, plants were individually covered with water-sealed acrylic cylinders as described above and fumigated with 1 ppm ethylene gas in air. Internode length in each position of rice stem was measured before, and $24 \mathrm{~h}$ after ethylene application.

1-MCP treatment. A commercially available blocker of ethylene receptor, 1methylcyclopropene (1-MCP), was used to examine the effect of endogenous ethylene on VOCs in rice plants, as advised in Schaller and Binder (2017). The 9-10 week-old plants were pretreated for $24 \mathrm{~h}$ with a final concentration of $100 \mathrm{ppm} 1-\mathrm{MCP}$ in air, and then used for WOS and control treatments as before. Both 1-MCP and control plants $(n=6-8)$ (without 1-MCP) were kept inside the air tight acrylic glass cylinders (20 cm diameter, $85 \mathrm{~cm}$ height) during treatments, and both sets were maintained under laboratory conditions.

Flooding treatment. To elucidate the VOC responses in flooded rice simultaneously challenged with WOS, 7 week-old plants were $90 \%$ flooded in water for $24 \mathrm{~h}$ using acrylic glass cylinder (20 cm diameter, $85 \mathrm{~cm}$ height) with open top. Plants were briefly removed from water, subjected to WOS treatment as described above, and returned in water for continued flooding stress. Exactly $4 \mathrm{~h}$ later, plants were removed from water and treated leaves were harvested for further analyses (VOC analysis and genes expression). As control, non-flooded control plants and those treated with WOS were maintained in a separate cultivation room with similar conditions to avoid cross-exposure to flood-released ethylene. Internode length was measured before, and $24 \mathrm{~h}$ after initiation of flooding stress.

Volatile extractions and analysis. Custom solid phase micro-extraction (SPME) method was used to collect broad range of volatiles from rice leaf tissues. Briefly, frozen leaves in $16 \mathrm{~mL}$ glass tubes were removed from $-80^{\circ} \mathrm{C}$ deep freezer, defrosted on ice, and then one MonoTrap (monolithic silica adsorbents; GL Sciences Inc., Japan) was suspended on a stainless steel pin inside of the PTFE (Polytetrafluoroethylene) lid, fitted with a nitrile rubber packing. Each sample was spiked with 400 ng tetralin (1,2,3,4-tetrahydronaphthalene; FUJIFILM Wako Pure Chemical Corporation) internal standard in dichloromethane (DCM; FUJIFILM Wako Pure Chemical Corporation) to the bottom of each tube containing plant tissue. After tightly closing, each tube with sample was inserted into a programmable heat block held at room temperature (aluminum block hole diameter $1.8 \mathrm{~cm}$; depth $6.5 \mathrm{~cm}$ ). Heat program was activated to bring the 
heat block to $150^{\circ} \mathrm{C}$, where temperature was held for $30 \mathrm{~min}$ before naturally cooling down to next preset temperature at $60^{\circ} \mathrm{C}$, and incubated for additional $30 \mathrm{~min}$ at $60{ }^{\circ} \mathrm{C}$. Each MonoTrap was detached from its lid, dried with gentle stream of nitrogen gas, and eluted with $200 \mu \mathrm{L}$ DCM into $1.5 \mathrm{~mL} \mathrm{GC}$ vials supplied with $375 \mu \mathrm{L}$ glass inserts (Tomsic Ltd., Japan). The whole assembly was sonicated in water bath sonicator for $5 \mathrm{~min}$, three times, with 2 min pause used between each round of sonication to allow sample cooling. Pins were carefully removed from each vial, together with the MonoTrap, before tightly closing vials with lids, and analyzing samples on automated GC-MS instrument.

Volatile compounds in DCM-eluted samples $(1 \mu \mathrm{L})$ were measured by GC-MS as described in Sobhy et al. (2017). Quantities of each reported volatile compound were calculated by comparison with the peak areas of a separately run authentic standards at concentration range 0.1-5 ng/ $\mu \mathrm{L}$, using a split injection ratio used for sample analysis (linalool, limonene, caryophyllene, $(E)$ - $\beta$-farnesene, methyl salicylate, $(Z)$-3-hexen-1-ol; FUJIFILM Wako Pure Chemical Corporation).

Phytohormone measurements. Phytohormone contents in collected leaf samples from WOS treatment and control at five plant developmental stages (6-10 weeks) were measured as described in Fukumoto et al. (2013).

Ethylene determination. Ethylene released from leaves of five plant developmental stages (6-10 weeks), or leaves from 7 week-old rice after flooding for $24 \mathrm{~h}$ (vs. air control), treated or untreated with WOS, was measured by a method adopted and modified from Helliwell et al. (2016), that is by incubating cut (i.e., wounded; W) leaf in a closed glass container for $24 \mathrm{~h}$. The youngest fully developed leaf from each stage was cut, quickly measured for fresh weight, inserted into glass tube (12 cm height, $2 \mathrm{~cm}$ diameter, $50 \mathrm{~mL}$ volume), and then tightly sealed with silicone plug. Leaves were incubated at normal light and temperature regime for $24 \mathrm{~h}$, and 1 $\mathrm{mL}$ of inside gas sample was removed from each tube with $1 \mathrm{~mL}$ syringe after inserting sharp needle with side hole through a soft silicon plug. Ethylene content was determined by gas chromatograph (GC-2014, Shimadzu, Japan) fitted with packed column ShinCarbon ST 50/80 (2.0 $\mathrm{m}$ length, $3 \mathrm{~mm}$ i.d., Shimadzu), using a standard flame ionization detector (FID). Helium gas carrier was used at $25 \mathrm{~mL} / \mathrm{min}$, injection port was held at $200{ }^{\circ} \mathrm{C}$, and oven temperature was programed to remain isocratic at $200^{\circ} \mathrm{C}$ during a 5 min run. 
Gene expression, quantitative RT-PCR. Transcript levels were quantified with qRT-PCR, essentially as described in Fukumoto et al. (2013). Gene-specific primer sequences forward/reverse $\left(5^{\prime} \rightarrow 3^{\prime}\right.$ ') used for qRT-PCR are described in Supplementary Table 1.

Statistical analyses. Statistical differences as indicated in legends were conducted with one-way analysis of variance (ANOVA) followed by Fisher's LSD test $(P<0.05)$, performed with an open source software OpenStat (http://statpages.info/miller/OpenStatMain.htm), or Student's $t$-test incorporated within the commercial version of Microsoft Excel (Microsoft Corporation, USA).

\section{Results}

\section{Developmental regulation of VOCs in rice}

We hypothesized that VOC production might be developmentally controlled in rice and checked the VOC contents in the leaves of synchronized six to ten week-old rice plants in the laboratory. To asses multiple VOCs, the youngest fully developed leaf was first wounded with a fabric pattern wheel, and then wounds treated with $20 \mu \mathrm{L}$ of diluted oral secretions (OS) from larvae of Mythimna loreyi (referred afterwards as simulated herbivory; or abbreviated as WOS in text and figures). Monoterpene linalool, measured $4 \mathrm{~h}$ after treatment, was strongly stimulated in the leaves at all growth stages, compared to control leaves without treatment, but induced linalool levels showed a peak accumulation in 8 week-old plants. Another monoterpene, limonene, accumulated constitutively in the leaves, and it only significantly increased by simulated herbivory in 8 week-old plants (Fig. 1A). Among sesquiterpenes, caryophyllene accumulated at all stages without substantial response to simulated herbivory, while $(E)$ - $\beta$-farnesene showed an induction profile similar to linalool (Fig. 1B). Although methyl salicylate (MeSA) was promoted by simulated herbivory at 6-8 weeks, older plants accumulated higher levels of MeSA, even without WOS treatment (Fig. 1C). (Z)-3-hexen-1-ol, a representative of green leaf volatiles (GLVs), accumulated more in the young leaves and declined in older plants. This compound was usually depleted by simulated herbivory (Fig. 1C), which is consistent with the expected escape of GLV from the open wound. Overall, multiple accumulation patterns among rice VOCs were observed, particularly revealing a transitional change in rice that occurs eight weeks after germination. We assumed that this change could be due to a differential ability of plants to produce signaling molecules, such as phytohormones, in response to external stress. 


\section{Hormonal responses in young rice development}

To address this possibility, phytohormone levels were determined in rice plants (6-10 weeks) before and after exposure to simulated herbivory. Leaves in the similar position as those used for VOC measurements were treated with WOS, and samples were collected $1 \mathrm{~h}$ later, to precede volatile biosynthesis determined $4 \mathrm{~h}$ post elicitation (Fig. 1). Compared to control leaves, JA strongly accumulated in WOS-treated leaves but these levels were not particularly different among developmental stages (Fig. 2A). In contrast, the highest level of JA-Ile occurred in the leaves of 8 week-old plants (Fig. 2A), showing an accumulation profile similar to linalool and (E)- $\beta$-farnesene (Fig. 1A, B). The abscisic acid (ABA) levels were not induced by simulated herbivory after $1 \mathrm{~h}$, showing slightly higher contents in 7 and 8 week-old plants (Fig. 2A). Interestingly, SA increased gradually in development, reaching the highest levels in the 9-10 week-old plants (Fig. 2A), providing a potential hormone pool for the high levels of MeSA found in older plants (Fig. 1). Finally, headspace levels of ethylene gas were measured after $24 \mathrm{~h}$ incubation of the cut leaves (wounded; W), and the leaves treated with simulated herbivory conducted briefly before cutting (WOS). Interestingly, the WOS-induced ethylene ontogenetic profile was negatively correlated (Pearson correlation $\mathrm{R}=-0.89 ; \mathrm{P}=0.042 ; \mathrm{n}=5$ ) to that of JA-Ile in WOS-treated leaves (Fig. 2A, B). However, JA-Ile was not significantly correlated with the ethylene released from the cut only leaves (W) (Pearson correlation $\mathrm{R}=-0.86 ; \mathrm{P}=0.061 ; \mathrm{n}=5$ ). As hormone profiles suggested (1) a positive role of JA-Ile, and (2) a negative role of ethylene in the developmentally-regulated production of inducible VOCs in rice, JA and ethylene signaling, as well as transcript levels of available VOC biosynthesis-related genes were investigated in detail.

\section{Transcriptional regulation of VOC production in rice leaves}

Defense responses in plants depend on the rapid, hormone-mediated transcriptional reprograming of stress-exposed plants, including genes involved in jasmonate/ethylene signaling, and those in VOC production. In 6-10 week-old plants, the transcripts of ALLENE OXIDE CYCLASE (OSAOC), a single copy gene in JA biosynthesis (Riemann et al., 2013), were already abundant in the untreated plants, and the levels further increased after simulated herbivory (Fig. 3A), showing a profile similar to induced JA levels (Fig. 2A). Similar transcriptional profiles were also found in other JA pathway-committed genes, LIPOXYGENASE 1 (OSLOXI), ALLENE OXIDE SYNTHASE 1 (OSAOS1), OXO-PHYTODIENOATE REDUCTASE 7 (OSOPR7), and 
OsCYP94C2b (for hydroxylation of JA-Ile) (Fig. 3A). The OsLOX9 and OsAOS2 transcripts showed a distinct regulation pattern, low in the younger plants but gradually increased in development (Fig. 3A). The chloroplast-localized PHOSPHOLIPASE Da4 (OsPLD $\alpha 4$ ), herbivory- and wound-induced gene implicated in release of linolenic acid from cell membranes (Qi et al., 2011), was highly upregulated by WOS, and it was similar to induced JA-Ile levels (Fig. 3A). Although we expected the JASMONATE RESISTANT 1 (OSJARl) profile to basically follow the induced JA-Ile levels (Fig. 2A), as this Gretchen Hagen 3.5 (GH3.5) gene family protein is responsible for JA-Ile biosynthesis (Fukumoto et al., 2013), induced OsJARI transcripts were highest in the leaves of 6 week-old rice, and gradually declined in development (Fig. 3A). The central regulator of jasmonate pathway, MYELOCYTOMATOSIS ONCOGENE TRANSCRIPTION FACTOR 2 (OSMYC2) transcripts were upregulated by WOS in a way similar to OSJARI (Fig. 3B), but induced profiles of two other jasmonate-responsive genes encoding for JAZ repressors, the JASMONATE ZIM-DOMAIN 9 (OsJAZ9) and OsJAZ11 (Ye et al., 2009), resembled to those of WOS-promoted JA-Ile accumulation (Fig. 3B). Among two SA- and JAinduced defense regulators in rice, OsWRKY45 (Shimono et al., 2007; 2012) and JAREGULATED MYB TRANSCRIPTION FACTOR (OsJAMYB) (Lee et al., 2001), respectively, only the second gene was significantly induced by simulated herbivory (Supplementary Fig. S1).

Transcript levels of the ethylene-responsive EIN3-BINDING F-BOX PROTEIN 1 gene (OsEBF1) (Ma et al., 2020) were examined along with JA markers (Fig. 4). As expected from ethylene data shown in Fig. 2B, lowest WOS-elicited levels of $O S E B F 1$ transcripts were detected in 8 weekold plants (Fig. 4B), further purporting the possibility of ethylene involvement in differential ontogenetic responses in rice. The ETHYLENE RESPONSE 2 (OSETR2), a receptor for ethylene (Watanabe et al., 2004), and four other genes putatively involved in ethylene biosynthesis, were investigated. The highest OsETR2 transcript levels in untreated plants occurred in 6-7 week-old rice, declined at 8-9 weeks, and then slightly increased again at 10 weeks (Fig. 4B). However, in contrast to the $O s E B F 1$ induction (Fig. 4B), simulated herbivory downregulated the OsETR2 transcripts, suggesting a negative feedback regulation in the ethylene receptor's function. The ethylene biosynthesis genes, 1-AMINOCYCLOPROPANE-1-CARBOXYLATE SYNTHASE 1 (OsACS1), OsACS3, 1-AMINOCYCLOPROPANE-1-CARBOXYLIC ACID OXIDASE 1 (OsACO1), and OsACO2 were generally higher, or more responsive to WOS in young plants (Fig. 4A). The positive regulatory gene in ethylene signaling, ETHYLENE INSENSITIVE3- 
LIKE1 (OsEIL1) (Mao et al., 2006) was moderately induced by simulated herbivory, showing somewhat lower levels of expression in 8-9 week-old rice (Fig. 4B).

In VOC biosynthesis, transcripts of 1-DEOXY-D-XYLULOSE 5-PHOSPHATE SYNTHASE 3 (OSDXS3) and LINALOOL SYNTHASE (OSLIS) were similar to linalool accumulation (Fig. 5), suggesting that linalool production is transcriptionally controlled at both, the input core methylerythritol 4-phosphate (MEP) pathway represented by OsDXS3, and the terminal terpene synthase, OsLIS. Similar regulation was found in the case of PHENYLALANINE AMMONIALYASE (OSPAL) and S-ADENOSYL-L-METHIONINE:SALICYLIC ACID CARBOXYL METHYLTRANSFERASE (OSSAMT), putatively involved in MeSA production in rice (Koo et $a l ., 2007)$. This was somewhat consistent with induced MeSA in young plants (6-8 weeks) but discrepant with the 8-10 week stages of development (Fig. 5, Fig. 1C). It suggests that in the older plants, another late development-associated methyltransferase and/or PAL could be additionally involved in MeSA production. The CARYOPHYLLENE SYNTHASE (OsCAS) transcripts were more constitutive across developmental stages, and suppressed by simulated herbivory, at least $1 \mathrm{~h}$ after the WOS treatment (Fig. 5). Finally, HYDOPEROXIDE LYASE 3 (OSHPL3) gene closely followed (Z)-3-hexen-1-ol (GLV) in the leaves, and showed partial suppression by simulated herbivory at some time points (Fig 5). In summary, overall transcript levels of VOC biosynthesis genes in rice were similar to those of VOC levels in the leaves, suggesting that gene expression is indicative of tissue capacity to produce volatiles.

\section{Ethylene treatment transcriptionally inhibits volatile production in rice}

Ethylene (1 ppm) exposure clearly inhibited accumulation of linalool, especially in the younger plants (Fig. 6A). The (E)- $\beta$-farnesene levels were also suppressed in young stages but accumulation of other volatiles was only slightly, or not affected by $4 \mathrm{~h}$ of ethylene application (Fig. 6A-C). As before, MeSA levels were constitutively higher in the older plants, and although MeSA was suppressed at some stages by ethylene, the resulting differences were not statistically significant (or only marginally significant at 9 weeks; $t$-test $\mathrm{P}=0.052$ ). In general, the rice VOCs that relied on the inducible transcripts were strongly affected by ethylene, suggesting that ethylene can specifically interfere with gene activation, with effective concentrations being equal to (or less than) 0.1 ppm (Fig. 6D, Supplementary Fig. S2). A time course experiment was conducted with 7 week-old rice treated with ethylene (1 ppm). Leaves were sampled before, 0.5 , 
1, and $4 \mathrm{~h}$ after WOS treatment in the presence or absence of exogenous ethylene (Figs. 7, 8, 9). Consistent with the previously reported dose-dependent response of the $O S E B F 1$ gene to ethylene (Ma et al., 2020), transcript levels of this marker gene were elevated by ethylene (Fig. 7). Ethylene receptor $O S E T R 2$ and signal transduction gene $O S E I L 1$ were also transcriptionally stimulated by ethylene while ethylene biosynthesis genes were not affected (Fig 7).

When we determined the JA and JA-Ile levels in the ethylene-treated leaves, JA was partially reduced but ethylene did not affect the early accumulation of JA-Ile (Fig 8A). A single copy $O S A O C$ gene transcripts were only partially suppressed by ethylene at $1 \mathrm{~h}$, at which similar trend was also found in $O S J A R I$ (Fig. 8B). The OsMYC2 transcript levels were induced early, showing slight but significant reduction by ethylene at 1 and $4 \mathrm{~h}$ post treatment (Fig. 5B), same as OSJAZ11 (Fig 5C). Interestingly, the OSJAZ9 transcripts that peaked slightly later, showed a much larger suppression by ethylene (Fig. 5C), suggesting that ethylene mainly affects the genes with late(r) response ( $\geq 1 \mathrm{~h}$ ) but largely avoids the early ( $\leq 1 \mathrm{~h}$ ) response genes, such as OsJAZ11 and $O S M Y C 2$. Among the other JA-related genes, OsPLDa4, OsAOS1 and OSOPR7 were all downregulated by ethylene in at least single time point but OsLOX9 (Fig 8B) and OSJAMYB (Supplementary Fig. S3) showed an induced expression pattern.

Finally, WOS-inducible $O S D X S 3, O S L I S, O s P A L$, and $O S S A M T$ were all significantly suppressed by ethylene (Fig. 9). Surprisingly, the $O S C A S$ and $O S H P L 3$ transcripts were also suppressed by ethylene, becoming significantly low after $4 \mathrm{~h}$ ethylene exposure (Fig. 9). It shows that while transcriptional repression of ethylene immediately affects the major herbivory-inducible VOCs, like linalool, it may also shut down the other volatiles later, including caryophyllene, and GLVs. However, persistent transcript levels and/or proteins seem to delay the visible impacts of ethylene, and sustain constant VOC levels in the leaves for at least 4 h, as shown in Fig. 6B, C. The complete loss of $O S C A S$ and $O S H P L 3$ transcripts in 4 h-ethylene-treated 6-10 week-old rice leaves and regulation of several other genes have been verified in an independent experiment conducted across five developmental stages of rice (Supplementary Figs. S4, S5). Here, the upregulation of ethylene marker gene $O s E B F 1$ across every developmental stage (Supplementary Fig. S5) was also confirmed.

\section{Examination of VOC-related physio-ecological functions of ethylene}


One of the best studied functions of ethylene in rice is flood-induced internode elongation. When 7 week-old rice plants were submerged in water, the last developed internode rapidly elongated within $24 \mathrm{~h}$ but only in submerged plants (Fig. 10A). As expected, ethylene that accumulated over 3 and $6 \mathrm{~h}$ time periods in the headspace of cut leaves was significantly higher in case of leaves previously exposed to flooding $(24 \mathrm{~h})$, relative to control rice maintained under ambient laboratory conditions (Fig 10C; Student's $t$-test, $P<0.01$ ). Interestingly, the flood-induced ethylene levels were further promoted by WOS treatment when it was applied along with the flooding stress (Fig. 10C). Exogenous ethylene (1 ppm) caused a faster elongation of rice but only at younger stages, which was particularly significant in 6 week-old rice (Fig. 10B). We hypothesize that such trends may naturally reflect the urgency of smaller plants to escape from the submergence and/or anoxia stress.

As high intracellular VOCs can potentially damage the plants, we hypothesized that submerged rice may stop producing VOCs, possibly by means of ethylene (Fig. 10C). The basal levels of linalool, (Z)-3-hexen-1-ol, and MeSA were not affected by flooding stress (Fig. 10D), showing that linalool and MeSA cannot be elicited by anoxia, and GLV pools remain stable despite constitutive $O s H L P 3$ transcript repression (Fig. 11A). In contrast, levels of linalool, (Z)-3-hexen1-ol, and MeSA in WOS-treated leaves were significantly suppressed by flooding stress (Fig. 10D). The $O S S A M T$ and $O S H P L 3$ transcripts were significantly reduced by flooding in simulated herbivory-treated leaves (Fig. 11A), thus corroborating the lower levels of MeSA and (Z)-3hexen-1-ol in submerged leaves treated with WOS (Fig. 10D). Notably, while the levels of $O S S A M T$ were effectively suppressed by submergence of plants, associated $O S P A L$ transcription was much less affected (Fig. 11A), suggesting that PAL may be an exempt from the ethylene control, possibly due to involvement in other functions, such as stem elongation under water. Consistent with the reduced levels of linalool in submerged leaves, OsDXS3 gene and several downstream genes in the core MEP pathway were suppressed by flooding (Fig. 12). However, submerged rice leaves treated with WOS showed an unexpectedly high levels of OsLIS transcripts, even higher than those found in the WOS-treated leaves under aerated conditions (Fig. 11A). It should be noted that the high transcript levels of OsLIS did not complement linalool production (Fig. 10D), most likely due to repression of multiple genes in the core MEP pathway (Fig. 12). Other genes, including the OsJAR1, OsMYC2, OsJAZ9, OsJAMYB, OsETR2, 
and $O s E B F 1$ (Fig. 11) showed expression patterns consistent with the exogenous ethylene treatments (Fig. 8, 9), further supporting the presence and function of endogenous ethylene in the flooded leaves.

As VOC levels substantially declined in 9-10 week-old plants, we speculated that ethylene (Fig. 2B), could be involved in this phenotype. To test this possibility, a half of 9 week-old plants were pretreated for $24 \mathrm{~h}$ with ethylene perception inhibitor, 1-methylcyclopropene (1-MCP), while the second half remained untreated. Then leaves from both control and 1-MCP exposed plants were subjected to simulated herbivory, or left untreated, and samples collected $4 \mathrm{~h}$ after the last treatment. As predicted, even untreated plants exposed to 1-MCP for $24 \mathrm{~h}$ could produce higher levels of mono- (linalool, limonene) and sesquiterpenes ( $(E)-\beta$-farnesene and caryophyllene), and these levels could be further enhanced by simulated herbivory (Fig. 13A, B). The transcripts of $O s L I S$ were only partially induced by 1 -MCP but upstream $O s D X S 3$ was highly upregulated (Fig. 14), supporting the observed increase in monoterpene levels (Fig 13A). The OsCAS transcription was significantly promoted by 1-MCP (Fig. 14), consistent with the increased carryophyllene levels (Fig. 13B). Consistent with the previous data, MeSA accumulation was not promoted by 1-MCP in mature plants (Fig. 13C), suggesting an involvement of yet another biosynthetic pathway for this compound at maturity. Alternatively, the lack of OSPAL induction by 1-MCP could explain the lack of MeSA promotion by 1-MCP, despite increase in OSSAMT transcript levels (Fig 14). Finally, the accumulation of (Z)-3-hexen1-ol was promoted by 1-MCP (Fig. 13C), suggesting that a natural decline in GLV content, particularly found at later developmental stages (Fig. 1C), could be due to increased level/sensitivity of/to ethylene in the older plants. The transcript levels of OSHPL3 and their upregulation by 1-MCP support this notion (Fig 14).

Although there are many other functions controlled by ethylene in rice, we provide first evidence that ethylene acts, among others, as an effective transcriptional repressor of VOC production in rice, possibly contributing to observed diversification of VOC blends in rice produced during stress and development.

\section{Discussion}


Plants evolved multiple stress response pathways to cope with variable environmental conditions in their lifetime. Typically, stress exposure causes rapid accumulation of secondary messengers, reactive oxygen species (ROS) and phytohormones that triggers stress-specific transcriptional reprograming, enabling increased resistance and/or tolerance of plants. Although regulatory mechanisms in plants responding to single stress, such as pathogens, herbivores, salinity, or drought are well studied, much less is known about the coordination of plant responses to simultaneously occurring stress conditions that presume active crosstalk among individual regulatory pathways. Here we address the role of ethylene and show that it serves as a contextdependent modulator of essential stress- and ontogeny-related VOCs in rice plants.

\section{Volatile production in rice is developmentally regulated}

Volatile emissions from both control and wounded rice leaves in the field greatly varied depending on developmental stages (Andama et al., 2020). When similar experiment was conducted under controlled laboratory conditions, rice leaves produced maximal amount of induced VOCs around eight weeks of age, confirming that rice VOC production is linked to ontogeny. Similarly, HIPV production in Datura wrightii was constrained by plant ontogeny to vegetative stages of growth, which could be partially restored by rejuvenation (Hare et al., 2010). In sagebrush, young plants have been more effective emitters of volatiles, as well as in perceiving volatile cues (Shiojiri and Karban, 2006). Vegetative stage soybean plants emitted 10fold more volatiles per biomass than reproductive plants, and young leaves emitted about three times more volatiles than older counterparts (Rostas and Eggert, 2008). Similarly, volatile production in maize not only dramatically declined in maturity but older plants produced a different blend of volatiles (Kollner et al., 2004). Production of extra floral nectar (EFN) for attraction of natural enemies of herbivores was also developmentally regulated in some plants (reviewed in Quintero et al., 2013). It has been proposed that such ontogenetic shifts are related to internal conditions of the plants, such as allocation costs, anatomical constraints, and external factors, for example seasonal variance in occurrence of herbivores and their natural enemies (Quintero et al., 2013). From virtual overlap of VOCs in Fig. 1, volatile blends in rice may greatly differ between young (6-week) and older (10-week) plants, with high and low proportion of GLVs, respectively, further differentiated by variable levels of MeSA. Natural enemies could even distinguish the 8-week stage of rice, based on the high linalool fraction in the herbivory- 
induced volatile blend (Fig. 1). This might be of a great ecological significance, as larvae of parasitoid wasps develop together with their host animal, and the remaining physiological time of the host plant can point out herbivores with sufficient life potential to support the entire natural enemy's larval cycle.

\section{JA-ethylene crosstalk in rice}

The VOCs, and especially HIPVs, are predominantly controlled by jasmonate signaling (Dicke and Baldwin, 2010; Joo et al., 2019). In order to understand the differential accumulation of VOCs in rice ontogeny (Fig. 1), we first examined phytohormone responses in young developed leaves. The maximal JA-Ile levels accumulated in 8 week-old rice (Fig. 2). In N. attenuata plants, herbivory-induced ethylene levels (and jasmonates) were significantly suppressed after flowering (Diezel et al., 2011). In rice, however, ethylene and expression of several ethylene response and biosynthetic genes attained minimal levels in 8-week stage, suggesting that JA-Ile and ethylene may work in opposite ways, as positive and negative regulators of VOCs, respectively. This was confirmed by exogenous application of ethylene, which triggered rapid transcriptional repression of VOC genes in rice. Interestingly, primary response genes in JA pathway, i.e., those induced by simulated herbivory within $30 \mathrm{~min}$, such as $O S M Y C 2$, were not substantially affected by the co-application of ethylene. However, other genes that peaked later $(1 \mathrm{~h})$ were significantly down-regulated by ethylene, which included the major herbivoryinducible VOC genes. Interestingly, even genes for constitutive VOCs, which primarily did not increase in response to WOS, such as $O S C A S$ and $O S H P L 3$ (Fig. 5), were eventually suppressed by ethylene at $4 \mathrm{~h}$ post treatment (Fig. 9, Supplementary Fig. S4). It suggests that even such volatile products may depend on jasmonate/ethylene crosstalk to keep their transcription, and volatile levels. In circadian genes, like OsCAS (Cheng et al., 2007), ethylene may also contribute to diurnal oscillations, together with the rhythmicity of jasmonates shown in Arabidopsis plants (Goodspeed et al., 2012).

A peculiar transcriptional pattern of $O S L I S$ was found in the flooding experiments. While other ethylene-sensitive genes, including $O S D X S 3, O S C A S, O S S A M T$, and $O S H P L 3$ were all suppressed by submergence (Fig. 11A), OsLIS transcript levels were highly upregulated by WOS that was combined with flooding stress (Fig. 11A). This result purports an existence of some additional regulatory mechanism(s) in OsLIS regulation, such as feedback control and/or 
posttranscriptional modifications. Alternatively, we cannot exclude a direct regulatory involvement of linalool (or its metabolite) in control of OSLIS. Previously, several monoterpenes were implicated as competitive inhibitors of ethylene perception (Grichko et al., 2003), suggesting that linalool (or other monoterpenes) could be directly interfering with ethylene signaling in the submerged plant tissues. Interestingly, this does not seem to happen when plants received ethylene under well aerated conditions (Fig. 9).

Furthermore, two JAZ repressors examined in our study, showed a differential transcriptional response to ethylene. While induced expression of OSJAZ11 basically followed the primary response regulator OsMYC2, elicited OsJAZ9 transcripts peaked about $30 \mathrm{~min}$ later, and they were substantially suppressed by ethylene (Fig. 8). Differential regulation of JAZ repressors provides yet another example of specialized JAZ function, first demonstrated in wild tobacco $N$. attenuata plants (Oh et al., 2012; Li et al., 2017). It also shows that while ethylene may regulate volatile branch of JA-Ile-mediated responses in rice, other JA defense signaling branches may be independent of ethylene. It will be important to systemically examine the response of other JAZ genes, and signaling components, to reveal the extent of ethylene control over canonical jasmonate pathway in rice, and vice versa.

\section{Ethylene in rice defense against herbivores}

Initially, it has been reported that ethylene positively contributes to VOC emissions in rice brown planthopper (BPH) (Nilaparvata lugens) infested rice (Lu et al., 2006). However, ethylene signaling was later shown to have contrasting effects on rice defense against chewing and piercing-sucking insects, striped stem borer (SSB) (Chilo supresalis), and BPH. While silencing of ethylene biosynthetic gene OsACS2 reduced resistance of rice to SSB, and suppressed SSBinduced volatiles, reduced ethylene levels in as-acs lines promoted plant resistance to BPH, and increased VOC emissions from the OsACS2-silenced rice (Lu et al., 2014). Such BPH-specific responses could be mediated by BPH-inducible F-box protein OsEBF1 that targets OsEIL1 regulator in ethylene signaling for proteasome degradation (Ma et al., 2020). In a functional test, overexpression of OsEBF1 and OsEIL1 suppressed and enhanced BPH performance in transgenic rice, respectively. As OsEIL1 acts on defense via promotion of OsLOX9 (also known as $O s H I-L O X)$ transcripts, ethylene and JA synergistically and negatively regulate $\mathrm{BPH}$ resistance in rice (Ma et al., 2020). Conversely, BPH resistance was promoted in another 
independent study using the OsHI-LOX-silenced rice plants with reduced JA levels (Zhou et al., 2009).

However, our data suggest that $O s L O X 9$ transcription may not be directly linked to JA/JA-Ile accumulation in WOS treatment simulating chewing herbivore attack (Fig. 3A), although its WOS-induced expression was promoted by ethylene (Fig. 8B), and thus consistent with the proposed role of OsEIL1 and ethylene as positive regulators of OsLOX9 (Ma et al., 2020). Overall, it seems that ethylene can regulate VOC production, both positively and negatively, depending on the feeding guild of attacking herbivore (Lu et al., 2014). Our study also reveals that experimental conditions, and especially plant age should be considered when studying JAethylene crosstalk in rice (Fig. 2). Furthermore, rice plants contain multiple ACS (5) and ACO (6) isoforms (Vu et al., 2012), and two differentially localized/expressed ethylene receptors, OsERF2 and OsERS1 (Iwai et al., 2006; Yu et al., 2017). Therefore, response to chewing and sucking insects could additionally involve spatiotemporal activation of multiple enzymes in ethylene pathway, resulting in complex patterns, and stress-adjustable plant responses. We recently found that rice plants react defensively to bacterial symbionts in BPH honeydew deposited on the rice leaves during feeding (Wari et al., 2019). Thus, BPH feeding may also trigger pathogen-related genes in ethylene biosynthesis (Yang et al., 2017), such as pathogeninducible OsACS1 and OsACO1 (Iwai et al., 2006), and specifically modulate SA/JA signaling in rice via ethylene during $\mathrm{BPH}$ attack.

\section{Ethylene functions as context-dependent regulator of VOCs in rice}

We also focused on basal rice physiology to further emphasize the importance of ethylene. Previously, a mutation in the volatile-specific ABC transporter, PhABCG1, caused overaccumulation of VOCs and internal cell damage in petunia flowers (Adebesin et al., 2017). Similar scenario could occur in the submerged rice leaves that, presumably, cannot release hydrophobic hydrocarbons (e.g., terpenes) to external environment. Additionally, VOCs as attractants of natural enemies, and natural enemies themselves, cannot function in submerged rice, thus making the production and release of VOCs undesirable/irrelevant. Along with this hypothesis, we show that the production of induced rice VOCs is blocked under flooding stress,

presumably as a result of flood-accumulated ethylene in the plant (Kende et al., 1998; Kuroha et al., 2018; Fig. 6C). In contrast to rice, partial flooding with a waterline $1 \mathrm{~cm}$ over the soil level 
caused elevation of SA biosynthesis in maize seedlings that increased the production of antiinsect C-glycosyl flavones (maysins) and herbivore-induced volatiles, benzyl acetate and phenethyl acetate, under combined flooding and herbivory stress (Block et al., 2020). In our experiments, ethylene was able to shut down the production of VOCs in rice older than 8 weeks. From our experience, leaves of mature rice are rarely attacked by chewing herbivores in the field, which is, at least in part, due to the silicon-impregnated non-glandular trichomes occurring on the surface of rice leaves (Andama et al., 2020). Therefore, rice plants at mature stage can fend-off most of their chewing enemies by mechanical barriers, and therefore, conserve available resources for reproduction and seed development, on account of defensive VOCs, which are repressed by ethylene.

\section{Supplementary Figures}

Fig. S1. Relative constitutive and induced transcript levels of additional stress-related genes in rice plants at different developmental stages.

Fig. S2. Dose-dependent effect of ethylene on VOC accumulation in rice leaves.

Fig. S3. Effect of ethylene application on OsWRKY45 and OsJAMYB signaling-related transcripts in rice.

Fig. S4. Effect of ethylene on selected set of VOC biosynthesis-related transcription in rice at $4 \mathrm{~h}$ post treatment in differently aged rice.

Fig. S5. Effect of ethylene on selected set of jasmonate/ethylene biosynthesis and signalingrelated transcripts in rice at $4 \mathrm{~h}$ post treatment in differently aged rice.

\section{Supplementary Tables}

Table S1. Oligonucleotide primers used in the study

\section{Data availability statement}


All data supporting the findings of this study are available within the paper and within its supplementary materials published online.

\section{Acknowledgements}

We thank Atsushi Miyake (Okayama University) for help with development of GC-MS methods used for volatile measurements; Dr. Hideyuki Matsuura (Hokkaido University) for providing deuterated jasmonate standards for LC-MS/MS; Dr. Yasutaka Kubo (Okayama University) for providing 1-MCP; Dr. David Wari for check of the manuscript. This work was supported by Ohara Foundation and Grants-in-Aid for Scientific Research (No. 24570026 and 16K08143 to I.G., No. 18 K05558 to T.S.). T.T. was supported by Pacific-LEADS program from JICA; I.S.S. by the JSPS postdoctoral fellowship P13379; and K.M. by IsDB 4 in 1 Project by Ministry of Research, Technology, and Higher Education, Republic of Indonesia.

\section{Figure legends}

Fig. 1. Ontogeny- and WOS-regulated accumulation of VOCs in rice leaves. Volatile compounds were determined by GC-MS in rice leaves of 6-10 week-old plants before, and $4 \mathrm{~h}$ after WOS elicitation. (A) Monoterpenes (linalool, limonene), (B) sesquiterpenes ((E)- $\beta$ farnesene, caryophyllene), (C) methyl salicylate, and GLV ((Z)-3-hexen-1-ol). Cont, control; WOS, wounding followed by application of $20 \mu \mathrm{L}$ diluted $M$. loreyi oral secretions. Statistical differences between pairs of control (Cont) and WOS-treated plants at each age were analyzed by Student's $t$-test ( $* P<0.05 ; * * P<0.01$; ns, not significant). Different letters (a-c, or A-D) indicate significant differences $(P<0.05)$ between different plant age determined separately for each group (Cont or WOS) by one-way ANOVA followed by Fisher's LSD test. W, weeks-old; FW, fresh weight; $n=5$; error bars=SE.

Fig. 2. Ontogeny- and WOS-regulated accumulation of phytohormones in rice leaves. (A) Jasmonic acid (JA), jasmonoyl-L-isoleucine (JA-Ile), abscisic acid (ABA), and salicylic acid (SA) levels were determined by LC-MS/MS in rice leaves of 6-10 week-old rice before, and $1 \mathrm{~h}$ after WOS elicitation. Cont, control; WOS, wounding followed by application of $20 \mu \mathrm{L}$ diluted 
M. loreyi oral secretions. (B) Ethylene produced by cut rice leaves of 6-10 week-old plants determined by GC-FID after $24 \mathrm{~h}$ accumulation period. Statistical differences between pairs of respective controls (Cont or Cut) and treatments (WOS or Cut+WOS) at each developmental stage were analyzed by Student's t-test $(* P<0.05$; $* * P<0.01$; ns, not significant). Different letters $(\mathrm{a}, \mathrm{b}$ or $\mathrm{A}, \mathrm{B})$ indicate significant differences $(P<0.05)$ between different plant stages determined separately for each group (Cont, WOS, Cut, and Cut+WOS) by one-way ANOVA followed by Fisher's LSD test. W, weeks-old; FW, fresh weight; $n=4-5$; error bars=SE.

Fig. 3. Relative transcript levels of jasmonate-related genes in rice plants at different developmental stages. Gene expression was determined by qRT-PCR in rice leaves of 6-10 week-old plants before, and $1 \mathrm{~h}$ after WOS elicitation. (A) Transcript levels of JA biosynthesis genes OsPLDa4, OsLOX1, OsLOX9, OsAOS1, OsAOS2, OsAOC, OsOPR7, OsJAR1 and OsCYP94C2b. (B) Transcript levels of JA signaling-related genes OsMYC2, OsJAZ9 and OsJAZ11. Cont, control; WOS, wounding followed by application of $20 \mu \mathrm{L}$ diluted M. loreyi oral secretions. Statistical differences between pairs of control (Cont) and WOS-treated plants at each stage were analyzed by Student's t-test $(* P<0.05$; $* * P<0.01$; ns, not significant). Different letters $(\mathrm{a}-\mathrm{c}$, or A-D) indicate significant differences $(\mathrm{p} \leq 0.05)$ between different plant age determined separately for each group (Cont or WOS) by one-way ANOVA followed by Fisher's LSD test. W, weeks-old; $n=5$; error bars $=\mathrm{SE}$.

Fig. 4. Relative transcript levels of ethylene-related genes in rice plants at different developmental stages. Gene expression was determined by qRT-PCR in rice leaves of 6-10 week-old plants before, and $1 \mathrm{~h}$ after WOS elicitation. (A) Transcript levels of ethylene biosynthesis genes OsACS1, OsACS3, OsACO1 and OsACO2. (B) Transcript levels of ethylene signaling-related genes OsETR2, OsEBF1 and OsEIL1. Cont, control; WOS, wounding followed by application of $20 \mu \mathrm{L}$ diluted $M$. loreyi oral secretions. Statistical differences between pairs of control (Cont) and WOS-treated plants at each age were analyzed by Student's t-test $(* P<0.05$; $* * P<0.01$; ns, not significant). Different letters (a-c, or A-C) indicate significant differences ( $\mathrm{p} \leq$ 0.05 ) between different plant age determined separately for each group (Cont or WOS) by oneway ANOVA followed by Fisher's LSD test. W, weeks-old; $n=5$; error bars=SE.

Fig. 5. Relative transcript levels of VOC-related genes in rice plants at different developmental stages. Gene expression was determined by qRT-PCR in rice leaves of 6-10 
week-old plants before, and $1 \mathrm{~h}$ after WOS elicitation and transcript levels of VOC biosynthesis related genes for terpenoids ( $\left.O_{s} D X S 3, O_{s} L I S, O s C A S\right)$, methyl salicylate $(O s P A L, O s S A M T)$, and GLVs (OsHPL3). Cont, control; WOS, wounding followed by application of $20 \mu \mathrm{L}$ diluted $M$. loreyi oral secretions. Statistical differences between pairs of control (Cont) and WOS-treated plants at each age were analyzed by Student's t-test $(* P<0.05 ; * * P<0.01$; ns, not significant). Different letters (a-c, or A-D) indicate significant differences $(P \leq 0.05)$ between different plant age determined separately for each group (Cont or WOS) by one-way ANOVA followed by Fisher's LSD test. W, weeks-old; $n=5$; error bars=SE.

Fig. 6. Effect of ethylene on ontogeny-dependent VOC accumulation in rice leaves. VOC levels were determined in leaves of 6-10 week-old plants treated with WOS, and inserted in closed containers containing ambient air (WOS), or in containers supplied with 1 ppm ethylene containing air (WOS+ET). Leaves were collected after $4 \mathrm{~h}$ incubation and analyzed by GC-MS. (A) Monoterpenes (linalool, limonene), (B) sesquiterpenes ((E)- $\beta$-farnesene, caryophyllene), (C) methyl salicylate, and GLV ((Z)-3-hexen-1-ol). (D) Effect of 0-100 ppm concentrations of ethylene on production of monoterpene linalool. In (A-C), statistical differences between pairs of WOS and WOS+ET treated plants at each age were separately analyzed by Student's t-test $(* P<0.05 ; * * P<0.01 ; \mathrm{ns}$, not significant). In (D), different letters $(\mathrm{a}, \mathrm{b})$ indicate significant differences between treatments $(P \leq 0.05)$ determined one-way ANOVA followed by Fisher's LSD test; $n=5$ (A-C); $n=3(\mathrm{D})$; error bars=SE.

Fig. 7. Effect of ethylene treatment on ethylene-biosynthesis and signaling-related genes in rice. Leaf samples were collected before and $0.5,1$, and $4 \mathrm{~h}$ after WOS treatment from plants kept in the presence (WOS+ET, dashed line) and absence (WOS, solid line) of ethylene (1 ppm). (A) Relative transcript levels of ethylene biosynthesis (OsACS1, OsACS3, OsACO1 and $O s A C O 2)$ and signaling (OsETR2, OsEBF1 and OsEIL1)-related genes. Statistical differences between treatments were analyzed at each time point by Student's t-test $(* P<0.05 ; * * P<0.01$; ns, not significant). $n=4$; error bars $=\mathrm{SE}$.

Fig. 8. Effect of ethylene on jasmonate levels and transcription of JA-biosynthesis and signaling-related genes in rice. Leaf samples were collected before and $0.5,1$, and $4 \mathrm{~h}$ after WOS treatment from plants kept in the presence (WOS+ET, dashed line) and absence (WOS, solid line) of ethylene (1 ppm). (A) JA and JA-Ile levels, (B) Relative transcript levels of JA 
biosynthesis (OsPLD 44 , OsLOX1, OsLOX9, OsAOS1, OsAOS2, OsAOC, OsOPR7, OsJAR1and $O s C Y P 94 C 2 b)$ and signaling (OsMYC2, OsJAZ9 and OsJAZ11)-related genes. Statistical differences between treatments were analyzed at each time point by Student's t-test $(* P<0.05$; $* * P<0.01$; ns, not significant). $n=4$; error bars $=\mathrm{SE}$.

Fig. 9. Effect of ethylene on VOC biosynthesis-related genes in rice. Leaf samples were collected before and $0.5,1$, and $4 \mathrm{~h}$ after WOS treatment from plants kept in the presence (WOS+ET, dashed line) and absence (WOS, solid line) of ethylene (1 ppm). Relative transcript levels of terpenoid ( $O s D X S 3, O s L I S, O s C A S)$, methyl salicylate (OsPAL, OsSAMT), and GLV (OsHPL3)-related genes. Statistical differences between treatments were analyzed at each time point by Student's t-test $(* P<0.05 ; * * P<0.01$; ns, not significant). $n=4$; error bars=SE.

Fig. 10. Ethylene functions in submergence responses of rice. (A) Individual internode lengths in 7 week-old rice plants kept under aerated (Air) or $24 \mathrm{~h}$ flooded (FL) conditions. (B) Effect of $1 \mathrm{ppm}$ ethylene applied for $24 \mathrm{~h}$ on relative elongation rate in rice determined as $\%$ elongation of stem relative to length prior start of treatment. (C) Rice plants were kept aerated (Air), or exposed to flooding stress for $24 \mathrm{~h}$ (FL), or flooded and treated with WOS (FL +WOS). Subsequently, ethylene was determined by GC-FID in head space of cut leaves incubated for 1, 3 and $6 \mathrm{~h}$ in the closed glass containers. (D) VOC levels in non-treated (Cont) and WOS-treated leaves from aerated (Air) and $24 \mathrm{~h}$ water-submerged (FL) rice. Samples were collected and analyzed $4 \mathrm{~h}$ after WOS treatment. Statistical differences between internode length (A), stem length at each stage (B), Air vs. FL treatments (C), and pairs of treatments (D) were analyzed by Student's t-test $(* P<0.05$; ns, not significant). Different letters of the same type (small, capital, capital italics) in $(C)$ indicate significant differences $(P<0.05)$ between treatments at each incubation time point determined one-way ANOVA followed by Fisher's LSD test. W, weeksold; FW, fresh weight; $n=5-6$; error bars=SE.

Fig. 11. Effect of water submergence on expression of JA/ethylene signaling and VOC biosynthesis genes. Rice plants at 7 weeks were submerged in water for $24 \mathrm{~h}$ (FL), or kept without water (Air), and subsequently treated with WOS, or left untreated (Cont). Samples were collected $1 \mathrm{~h}$ after last treatment and analyzed by qRT-PCR. (A) VOC biosynthesis-related genes (OsLIS, OsCAS, OsPAL, OsSAMT, OsHPL3), (B) JA biosynthesis/signaling-related genes (OsJAR1, OsMYC2, OsJAZ9, OsJAZ11, OsJAMYB) and ethylene biosynthesis/signaling genes 
(OsACS1, OsETR2, OsEBF1). Statistical differences between pairs of flooded and air samples were analyzed by Student's t-test $(* P<0.05$, $* * P<0.01$; ns, not significant). Arrows show suppression or induction of transcripts by flooding stress. $n=6$; error bars=SE.

Fig. 12. Effect of water submergence on expression of monoterpenoid pathway genes. Rice plants at 7 weeks were submerged in water for $24 \mathrm{~h}$ (FL), or kept without water (Air), and subsequently treated with WOS, or left untreated (Cont). Samples were collected $1 \mathrm{~h}$ after last treatment and analyzed by qRT-PCR. Transcript levels of methylerythritol 4-phosphate (MEP) pathway-related genes (OSDXS3), 1-DEOXY-D-XYLULOSE 5-PHOSPHATE REDUCTOISOMERASE (OSDXR), 4-(CYTIDINE 5'-DIPHOSPHO)-2-C-METHYL-DERYTHRITOL SYNTHASE (OSCMS), 4-DIPHOSPHOCYTIDYL-2-C-METHYL-DERYTHRITOL KINASE (OSCMK), 2-C-METHYL-D-ERYTHRITOL 2,4-CYCLODIPHOSPHATE SYNTHASE (OSMCS), 1-HYDROXY-2-METHYL-2-(E)-BUTENYL 4-DIPHOSPHATE SYNTHASE (OSHDS) and 1-HYDROXY-2-METHYL-2-(E)-BUTENYL 4-DIPHOSPHATE REDUCTASE (OsHDR). Statistical differences between pairs of flooded and air samples were analyzed by Student's t-test $(* * P<0.01$; ns, not significant). Arrows show suppression transcripts by flooding stress. $n=6$; error bars $=\mathrm{SE}$.

Fig. 13. Effect of ethylene inhibitor 1-MCP on VOC production in rice. Rice plants at 9 weeks were pretreated with 20 ppm 1-MCP-containing air for $24 \mathrm{~h}$ (1-MCP), or kept in container with ambient air without ethylene inhibitor (Air), and subsequently treated with WOS, or left untreated (Cont). Samples for VOC analysis were collected after $4 \mathrm{~h}$ and analyzed by GC-MS. (A) Monoterpenes (linalool, limonene), (B) sesquiterpenes ((E)- $\beta$ farnesene, caryophyllene), (C) methyl salicylate, and GLV ((Z)-3-hexen-1-ol). Statistical differences between pairs of 1-MCPtreated and air samples were analyzed by Student's t-test $(* P<0.05, * * P<0.01$; ns, not significant). FW, fresh weight; $n=6$; error bars $=\mathrm{SE}$.

Fig. 14. Effect of ethylene inhibitor 1-MCP on gene expression in rice. Rice plants at 9 weeks were pretreated with 20 ppm 1-MCP-containing air for $24 \mathrm{~h}$ (1-MCP), or kept in container with ambient air without ethylene inhibitor (Air), and subsequently treated with WOS, or left untreated (Cont). Samples for transcript analysis were collected $1 \mathrm{~h}$ after the last treatment. (A) Transcript levels of monoterpene-related $O s D X S 3$ and $O s L I S$; (B) MeSA-related $O S P A L$ and OsSAMT; and (C) GLV-related OsHPL3. Statistical differences between pairs of 1-MCP-treated 
and air samples were analyzed by Student's t-test $(* P<0.05, * * P<0.01$; ns, not significant). FW, fresh weight; $n=6$; error bars=SE.

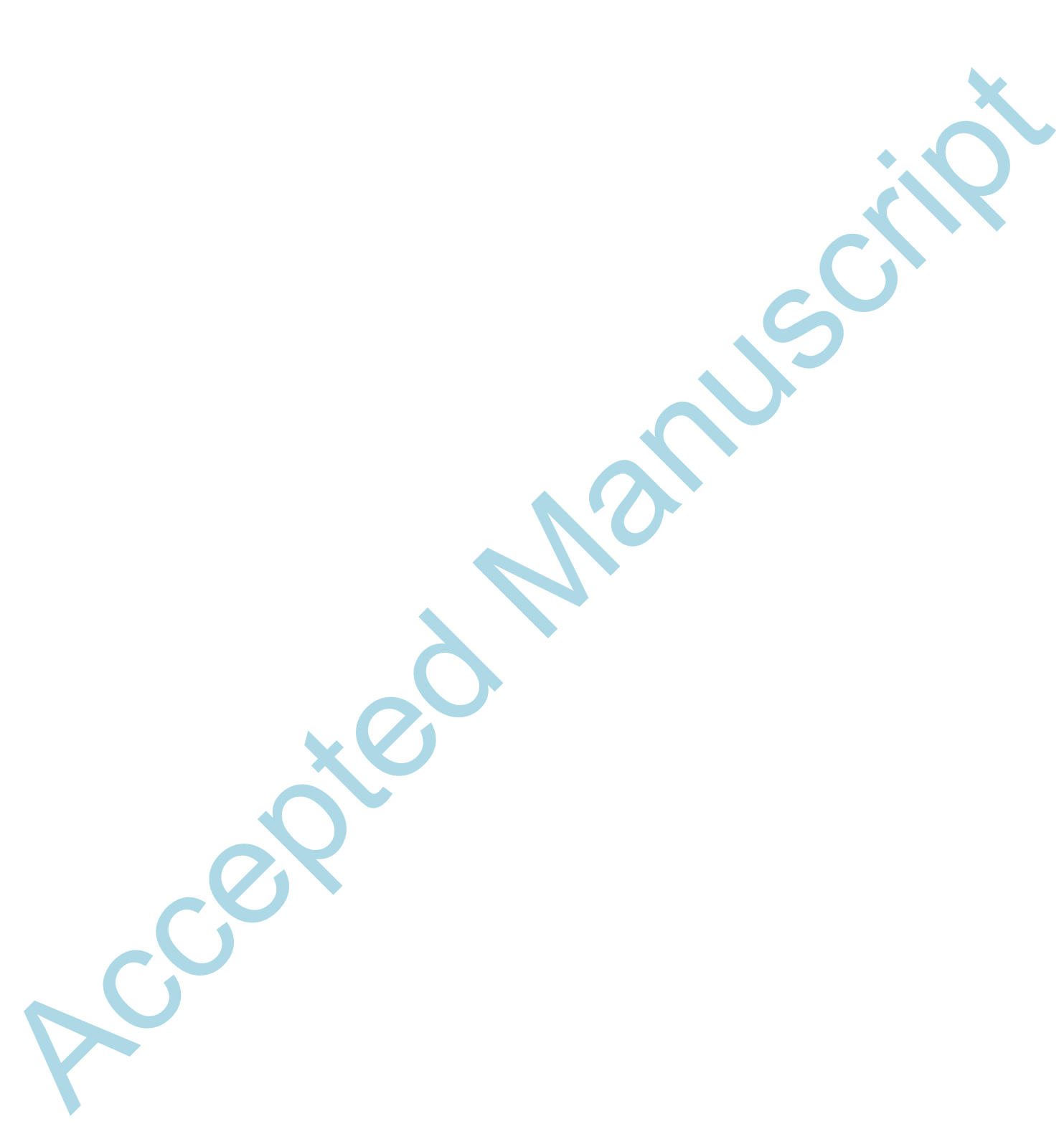




\section{Reference list}

Adebesin F, Widhalm JR, Boachon B, Lefevre F, Pierman B, Lynch JH, Alam I, Junqueira B, Benke R, Ray S, Porter JA, Yanagisawa M, Wetzstein HY, Morgan JA, Boutry M, Schuurink RC, Dudareva N. 2017. Emission of volatile organic compounds from petunia flowers is facilitated by an ABC transporter. Science 356, 1386-1388.

Andama JB, Mujiono K, Hojo Y, Shinya T, Galis I. Non-glandular silicified trichomes are essential for rice defense against chewing herbivores. Plant Cell and Environment, https://doi.org/10.1111/pce.13775.

Arimura G, Matsui K, Takabayashi J. 2009. Chemical and molecular ecology of herbivore-induced plant volatiles: Proximate factors and their ultimate functions. Plant and Cell Physiology 50, 911-923.

Arimura GI, Garms S, Maffei M, Bossi S, Schulze B, Leitner M, Mithoefer A, Boland W. 2008. Herbivore-induced terpenoid emission in Medicago truncatula: concerted action of jasmonate, ethylene and calcium signaling. Planta 227, 453-464.

Block AK, Hunter CT, Sattler SE, Rering C, McDonald S, Basset GJ, Christensen SA. 2020. Fighting on two fronts: Elevated insect resistance in flooded maize. Plant Cell and Environment 43, 223-234.

Booker MA, DeLong A. 2015. Producing the ethylene signal: Regulation and diversification of ethylene biosynthetic enzymes. Plant Physiology 169, 42-50.

Brilli F, Loreto F, Baccelli I. 2019. Exploiting plant volatile organic compounds (VOCs) in agriculture to improve sustainable defense strategies and productivity of crops. Frontiers in Plant Science 10, 264.

Broekgaarden C, Caarls L, Vos IA, Pieterse CMJ, Van Wees SCM. 2015. Ethylene: Traffic controller on hormonal crossroads to defense. Plant Physiology 169, 2371-2379.

Bruce TJA. 2015. Interplay between insects and plants: dynamic and complex interactions that have coevolved over millions of years but act in milliseconds. Journal of Experimental Botany 66, 455-465.

Cheng AX, Xiang CY, Li JX, Yang CQ, Hu WL, Wang LJ, Lou YG, Chen XY. 2007. The rice (E)-beta-caryophyllene synthase (OsTPS3) accounts for the major inducible volatile sesquiterpenes. Phytochemistry 68, 1632-1641.

Christensen SA, Nemchenko A, Borrego E, Murray I, Sobhy IS, Bosak L, DeBlasio S, Erb M, Robert CAM, Vaughn KA, Herrfurth C, Tumlinson J, Feussner I, Jackson D, Turlings TCJ, Engelberth J, Nansen C, Meeley R, Kolomiets MV. 2013. The maize lipoxygenase, ZmLOX10, mediates green leaf volatile, jasmonate and herbivore-induced plant volatile production for defense against insect attack. Plant Journal 74, 59-73.

Dicke M, Baldwin IT. 2010. The evolutionary context for herbivore-induced plant volatiles: beyond the 'cry for help'. Trends in Plant Science 15, 167-175. 
Dicke M, van Loon JJA, Soler R. 2009. Chemical complexity of volatiles from plants induced by multiple attack. Nature Chemical Biology 5, 317-324.

Diezel C, Allmann S, Baldwin IT. 2011. Mechanisms of optimal defense patterns in Nicotiana attenuata: Flowering attenuates herbivory-elicited ethylene and jasmonate signaling. Journal of Integrative Plant Biology 53, 971-983.

Dudareva N, Negre F, Nagegowda DA, Orlova I. 2006. Plant volatiles: Recent advances and future perspectives. Critical Reviews in Plant Sciences 25, 417-440.

Erb M. 2018. Volatiles as inducers and suppressors of plant defense and immunity - origins, specificity, perception and signaling. Current Opinion in Plant Biology 44, 117-121.

Fukumoto K, Alamgir KM, Yamashita Y, Mori IC, Matsuura H, Galis I. 2013. Response of rice to insect elicitors and the role of OsJAR1 in wound and herbivory-induced JA-Ile accumulation. Journal of Integrative Plant Biology 55, 775-784.

Goodspeed D, Chehab EW, Min-Venditti A, Braam J, Covington MF. 2012. Arabidopsis synchronizes jasmonate-mediated defense with insect circadian behavior. Proceedings of the National Academy of Sciences of the United States of America 109, 4674-4677.

Grichko VP, Sisler EC, Seek M. 2003. Anti-ethylene properties of monoterpenes and some other naturally occurring compounds in plants. SAAS bulletin, biochemistry and biotechnology 16, 20-27.

Hare JD. 2010. Ontogeny and season constrain the production of herbivore-inducible plant volatiles in the field. Journal of Chemical Ecology 36, 1363-1374.

Helliwell EE, Wang Q, Yang YN. 2016. Ethylene biosynthesis and signaling is required for rice immune response and basal resistance against Magnaporthe oryzae infection. Molecular Plant-Microbe Interactions 29, 831-843.

Hilker M, Meiners T. 2010. How do plants "notice" attack by herbivorous arthropods? Biological Reviews 85, 267-280.

Horiuchi J, Arimura G, Ozawa R, Shimoda T, Takabayashi J, Nishioka T. 2001. Exogenous ACC enhances volatiles production mediated by jasmonic acid in lima bean leaves. Febs Letters 509, 332-336.

Huang J, Schmelz EA, Alborn H, Engelberth J, Tumlinson JH. 2005. Phytohormones mediate volatile emissions during the interaction of compatible and incompatible pathogens: The role of ethylene in Pseudomonas syringae infected tobacco. Journal of Chemical Ecology 31, 439-459.

Huffaker A, Pearce G, Veyrat N, Erb M, Turlings TCJ, Sartor R, Shen ZX, Briggs SP, Vaughan MM, Alborn HT, Teal PEA, Schmelz EA. 2013. Plant elicitor peptides are conserved signals regulating direct and indirect antiherbivore defense. Proceedings of the National Academy of Sciences of the United States of America 110, 5707-5712. 
Iwai T, Miyasaka A, Seo S, Ohashi Y. 2006. Contribution of ethylene biosynthesis for resistance to blast fungus infection in young rice plants. Plant Physiology 142, 1202-1215.

Iwamoto M, Baba-Kasai A, Kiyota S, Hara N, Takano M. 2010. ACO1, a gene for aminocyclopropane-1-carboxylate oxidase: effects on internode elongation at the heading stage in rice. Plant Cell and Environment 33, 805-815.

Joo Y, Schuman MC, Goldberg JK, Wissgott A, Kim SG, Baldwin IT. 2019. Herbivory elicits changes in green leaf volatile production via jasmonate signaling and the circadian clock. Plant Cell and Environment 42, 972-982.

Junker RR, Tholl D. 2013. Volatile organic compound mediated interactions at the plantmicrobe interface. Journal of Chemical Ecology 39, 810-825.

Karban R, Baldwin IT, Baxter KJ, Laue G, Felton GW. 2000. Communication between plants: induced resistance in wild tobacco plants following clipping of neighboring sagebrush. Oecologia 125, 66-71.

Kende H, van der Knaap E, Cho HT. 1998. Deepwater rice: A model plant to study stem elongation. Plant Physiology 118, 1105-1110.

Kessler A, Baldwin IT. 2001. Defensive function of herbivore-induced plant volatile emissions in nature. Science 291, 2141-2144.

Kollner TG, Schnee C, Gershenzon J, Degenhardt J. 2004. The sesquiterpene hydrocarbons of maize (Zea mays) form five groups with distinct developmental and organspecific distribution. Phytochemistry 65, 1895-1902.

Koo AJK, Howe GA. 2009. The wound hormone jasmonate. Phytochemistry 70, 1571-1580.

Koo YJ, Kim MA, Kim EH, Song JT, Jung C, Moon JK, Kim JH, Seo HS, Song SI, Kim JK, Lee JS, Cheong JJ, Do Choi Y. 2007. Overexpression of salicylic acid carboxyl methyltransferase reduces salicylic acid-mediated pathogen resistance in Arabidopsis thaliana. Plant Molecular Biology 64, 1-15.

Kuroha T, Nagai K, Gamuyao R, Wang DR, Furuta T, Nakamori M, Kitaoka T, Adachi K, Minami A, Mori Y, Mashiguchi K, Seto Y, Yamaguchi S, Kojima M, Sakakibara H, Wu JZ, Ebana K, Mitsuda N, Ohme-Takagi M, Yanagisawa S, Yamasaki M, Yokoyama R, Nishitani K, Mochizuki T, Tamiya G, McCouch SR, Ashikari M. 2018. Ethylenegibberellin signaling underlies adaptation of rice to periodic flooding. Science 361, 181-185.

Kusajima M, Shima S, Fujita M, Minamisawa K, Che FS, Yamakawa H, Nakashita H. 2018. Involvement of ethylene signaling in Azospirillum sp B510-induced disease resistance in rice. Bioscience Biotechnology and Biochemistry 82, 1522-1526.

Larsen PB. 2015. Mechanisms of ethylene biosynthesis and response in plants. In: Guilfoyle T, Hagen G, eds. Plant Hormone Signalling, Vol. 58, 61-70.

Lee MW, Qi M, Yang YO. 2001. A novel jasmonic acid-inducible rice myb gene associates with fungal infection and host cell death. Molecular Plant-Microbe Interactions 14, 527-535. 
Li R, Wang M, Wang Y, Schuman MC, Weinhold A, Schafer M, Jimenez-Aleman GH, Barthel A, Baldwin IT. 2017. Flower-specific jasmonate signaling regulates constitutive floral defenses in wild tobacco. Proceedings of the National Academy of Sciences of the United States of America 114, E7205-E7214.

Lu J, Li JC, Ju HP, Liu XL, Erb M, Wang X, Lou YG. 2014. Contrasting effects of ethylene biosynthesis on induced plant resistance against a chewing and a piercing-sucking herbivore in rice. Molecular Plant 7, 1670-1682.

Lu YJ, Wang X, Lou YG, Cheng JA. 2006. Role of ethylene signaling in the production of rice volatiles induced by the rice brown planthopper Nilaparvata lugens. Chinese Science Bulletin 51, 2457-2465.

Ma FL, Yang XF, Shi ZY, Miao XX. 2020. Novel crosstalk between ethylene- and jasmonic acid-pathway responses to a piercing-sucking insect in rice. New Phytologist 225, 474-487.

Maffei ME, Arimura GI, Mithofer A. 2012. Natural elicitors, effectors and modulators of plant responses. Natural Product Reports 29, 1288-1303.

Mao CZ, Wang SM, Jia QJ, Wu P. 2006. OsEIL1, a rice homolog of the Arabidopsis EIN3 regulates the ethylene response as a positive component. Plant Molecular Biology 61, 141152.

Mewis I, Appel HM, Hom A, Raina R, Schultz JC. 2005. Major signaling pathways modulate Arabidopsis glucosinolate accumulation and response to both phloem-feeding and chewing insects. Plant Physiology 138, 1149-1162.

Mitalo OW, Tokiwa S, Kondo Y, Otsuki T, Galis I, Suezawa K, Kataoka I, Doan AT, Nakano R, Ushijima K, Kubo Y. 2019. Low temperature storage stimulates fruit softening and sugar accumulation without ethylene and aroma volatile production in kiwifruit. Frontiers in Plant Science 10, 888.

Mithofer A, Boland W. 2012. Plant defense against herbivores: Chemical aspects. In: Merchant SS, ed. Annual Review of Plant Biology, Vol. 63, 431-450.

Oh Y, Baldwin IT, Galis I. 2012. NaJAZh regulates a subset of defense responses against herbivores and spontaneous leaf necrosis in Nicotiana attenuata plants. Plant Physiology 159, $769-788$.

Pare PW, Tumlinson JH. 1999. Plant volatiles as a defense against insect herbivores. Plant Physiology 121, 325-331.

Paudel JR, Bede JC. 2015. Ethylene signaling modulates herbivore-induced defense responses in the model legume Medicago truncatula. Molecular Plant-Microbe Interactions 28, 569-579.

Pichersky E, Gershenzon J. 2002. The formation and function of plant volatiles: perfumes for pollinator attraction and defense. Current Opinion in Plant Biology 5, 237-243. 
Pierik R, Ballare CL, Dicke M. 2014. Ecology of plant volatiles: taking a plant community perspective. Plant Cell and Environment 37, 1845-1853.

Qi JF, Zhou GX, Yang LJ, Erb M, Lu YH, Sun XL, Cheng JA, Lou YG. 2011. The chloroplast-localized phospholipases D alpha 4 and alpha 5 regulate herbivore-induced direct and indirect defenses in rice. Plant Physiology 157, 1987-1999.

Quintero C, Barton KE, Boege K. 2013. The ontogeny of plant indirect defenses. Perspectives in Plant Ecology Evolution and Systematics 15, 245-254.

Rehrig EM, Appel HM, Jones AD, Schultz JC. 2014. Roles for jasmonate- and ethyleneinduced transcription factors in the ability of Arabidopsis to respond differentially to damage caused by two insect herbivores. Frontiers in Plant Science 5, 407.

Riemann M, Haga K, Shimizu T, Okada K, Ando S, Mochizuki S, Nishizawa Y, Yamanouchi U, Nick P, Yano M, Minami E, Takano M, Yamane H, Iino M. 2013. Identification of rice Allene Oxide Cyclase mutants and the function of jasmonate for defence against Magnaporthe oryzae. Plant Journal 74, 226-238.

Rodriguez A, Alquezar B, Pena L. 2013. Fruit aromas in mature fleshy fruits as signals of readiness for predation and seed dispersal. New Phytologist 197, 36-48.

Rostas M, Eggert K. 2008. Ontogenetic and spatio-temporal patterns of induced volatiles in Glycine max in the light of the optimal defence hypothesis. Chemoecology 18, 29-38.

Schaffer RJ, Friel EN, Souleyre EJF, Bolitho K, Thodey K, Ledger S, Bowen JH, Ma JH, Nain B, Cohen D, Gleave AP, Crowhurst RN, Janssen BJ, Yao JL, Newcomb RD. 2007. A genomics approach reveals that aroma production in apple is controlled by ethylene predominantly at the final step in each biosynthetic pathway. Plant Physiology 144, 18991912.

Schaller GE, Binder BM. 2017. Inhibitors of ethylene biosynthesis and signaling. In: Binder BM, Schaller GE, eds. Ethylene Signaling: Methods and Protocols, Vol. 1573: Springer Science+Business Media LLC, 223-235.

Schiestl FP. 2015. Ecology and evolution of floral volatile-mediated information transfer in plants. New Phytologist 206, 571-577.

Schmelz EA, Alborn HT, Banchio E, Tumlinson JH. 2003. Quantitative relationships between induced jasmonic acid levels and volatile emission in Zea mays during Spodoptera exigua herbivory. Planta 216, 665-673.

Schuman MC, Meldau S, Gaquerel E, Diezel C, McGale E, Greenfield S, Baldwin IT. 2018. The active jasmonate JA-Ile regulates a specific subset of plant jasmonate-mediated resistance to herbivores in nature. Frontiers in Plant Science 9, 787.

Shimono M, Koga H, Akagi A, Hayashi N, Goto S, Sawada M, Kurihara T, Matsushita A, Sugano S, Jiang CJ, Kaku H, Inoue H, Takatsuji H. 2012. Rice WRKY45 plays important roles in fungal and bacterial disease resistance. Molecular Plant Pathology 13, 8394. 
Shimono M, Sugano S, Nakayama A, Jiang CJ, Ono K, Toki S, Takatsuji H. 2007. Rice WRKY45 plays a crucial role in benzothiadiazole-inducible blast resistance. Plant Cell 19, 2064-2076.

Shinya T, Hojo Y, Desaki Y, Christeller JT, Okada K, Shibuya N, Galis I. 2016.

Modulation of plant defense responses to herbivores by simultaneous recognition of different herbivore-associated elicitors in rice. Scientific Reports 6, 32537.

Shiojiri K, Karban R. 2006. Plant age, communication, and resistance to herbivores: young sagebrush plants are better emitters and receivers. Oecologia 149, 214-220.

Sobhy IS, Miyake A, Shinya T, Galis I. 2017. Oral secretions affect HIPVs induced by generalist (Mythimna loreyi) and specialist (Parnara guttata) herbivores in rice. Journal of Chemical Ecology 43, 929-943.

Stotz HU, Pittendrigh BR, Kroymann J, Weniger K, Fritsche J, Bauke A, Mitchell-Olds T. 2000. Induced plant defense responses against chewing insects. Ethylene signaling reduces resistance of Arabidopsis against Egyptian cotton worm but not diamondback moth. Plant Physiology 124, 1007-1017.

Sugimoto K, Matsui K, Iijima Y, Akakabe Y, Muramoto S, Ozawa R, Uefune M, Sasaki R, Alamgir KM, Akitake S, Nobuke T, Galis I, Aoki K, Shibata D, Takabayashi J. 2014. Intake and transformation to a glycoside of (Z)-3-hexenol from infested neighbors reveals a mode of plant odor reception and defense. Proceedings of the National Academy of Sciences of the United States of America 111, 7144-7149.

Turlings TCJ, Tumlinson JH. 1992. Systemic release of chemical signals by herbivoreinjured corn. Proceedings of the National Academy of Sciences of the United States of America 89, 8399-8402.

van Loon LC, Geraats BPJ, Linthorst HJM. 2006. Ethylene as a modulator of disease resistance in plants. Trends in Plant Science 11, 184-191.

Verhage A, van Wees SCM, Pieterse CMJ. 2010. Plant immunity: It's the hormones talking, but what do they say? Plant Physiology 154, 536-540.

Voelckel C, Schittko U, Baldwin IT. 2001. Herbivore-induced ethylene burst reduces fitness costs of jasmonate- and oral secretion-induced defenses in Nicotiana attenuata. Oecologia 127, 274-280.

von Dahl CC, Winz RA, Halitschke R, Kuhnemann F, Gase K, Baldwin IT. 2007. Tuning the herbivore-induced ethylene burst: the role of transcript accumulation and ethylene perception in Nicotiana attenuata. Plant Journal 51, 293-307.

Vu HTT, Manangkil OE, Mori N, Yoshida S, Nakamura C. 2012. Induction and repression of gene expression mediating ethylene biosynthesis and sodium/proton exchange in rice seedlings under submergence stress. Biotechnology \& Biotechnological Equipment 26, 2945-2951. 
War AR, Paulraj MG, Ahmad T, Buhroo AA, Hussain B, Ignacimuthu S, Sharma HC. 2012. Mechanisms of plant defense against insect herbivores. Plant Signaling \& Behavior 7, 1306-1320.

War AR, Sharma HC, Paulraj MG, War MY, Ignacimuthu S. 2011. Herbivore induced plant volatiles. Plant Signaling \& Behavior 6, 1973-1978.

War AR, Taggar GK, Hussain B, Taggar MS, Nair RM, Sharma HC. 2018. Plant defence against herbivory and insect adaptations. AoB PLANTS 10, ply037.

Wari D, Kabir MA, Mujiono K, Hojo Y, Shinya T, Tani A, Nakatani H, Galis I. 2019. Honeydew-associated microbes elicit defense responses against brown planthopper in rice. Journal of Experimental Botany 70, 1683-1696.

Wasternack C, Hause B. 2013. Jasmonates: biosynthesis, perception, signal transduction and action in plant stress response, growth and development. An update to the 2007 review in Annals of Botany. Annals of Botany 111, 1021-1058.

Watanabe H, Saigusa M, Hase S, Hayakawa T, Satoh S. 2004. Cloning of a cDNA encoding an ETR2-like protein (Os-ERL1) from deep water rice (Oryza sativa L.) and increase in its mRNA level by submergence, ethylene, and gibberellin treatments. Journal of Experimental Botany 55, 1145-1148.

Wu JQ, Baldwin IT. 2010. New insights into plant responses to the attack from insect herbivores. In: Campbell A, Lichten M, Schupbach G, eds. Annual Review of Genetics, Vol. $44,1-24$.

Yang C, Li W, Cao JD, Meng FW, Yu YQ, Huang JK, Jiang L, Liu MX, Zhang ZG, Chen XW, Miyamoto K, Yamane H, Zhang JS, Chen SY, Liu J. 2017. Activation of ethylene signaling pathways enhances disease resistance by regulating ROS and phytoalexin production in rice. Plant Journal 89, 338-353.

Ye HY, Du H, Tang N, Li XH, Xiong LZ. 2009. Identification and expression profiling analysis of TIFY family genes involved in stress and phytohormone responses in rice. Plant Molecular Biology 71, 291-305.

Yu MD, Yau CP, Yip WK. 2017. Differentially localized rice ethylene receptors OsERS1 and OsETR2 and their potential role during submergence. Plant Signaling \& Behavior 12, e1356532.

Zeng LT, Wang XQ, Kang M, Dong F, Yang ZY. 2017. Regulation of the rhythmic emission of plant volatiles by the circadian clock. International Journal of Molecular Sciences 18, 2408.

Zhang PJ, Broekgaarden C, Zheng SJ, Snoeren TAL, van Loon JJA, Gols R, Dicke M. 2013. Jasmonate and ethylene signaling mediate whitefly-induced interference with indirect plant defense in Arabidopsis thaliana. New Phytologist 197, 1291-1299. 
Zhou GX, Qi JF, Ren N, Cheng JA, Erb M, Mao BZ, Lou YG. 2009. Silencing OsHILOX makes rice more susceptible to chewing herbivores, but enhances resistance to a phloem feeder. Plant Journal 60, 638-648.

Zhu HL, Zhu BZ, Fu DQ, Xie YH, Hao YL, Luo YB. 2005. Role of ethylene in the biosynthetic pathways of aroma volatiles in ripening fruit. Russian Journal of Plant Physiology 52, 691-695. 
Figure 1
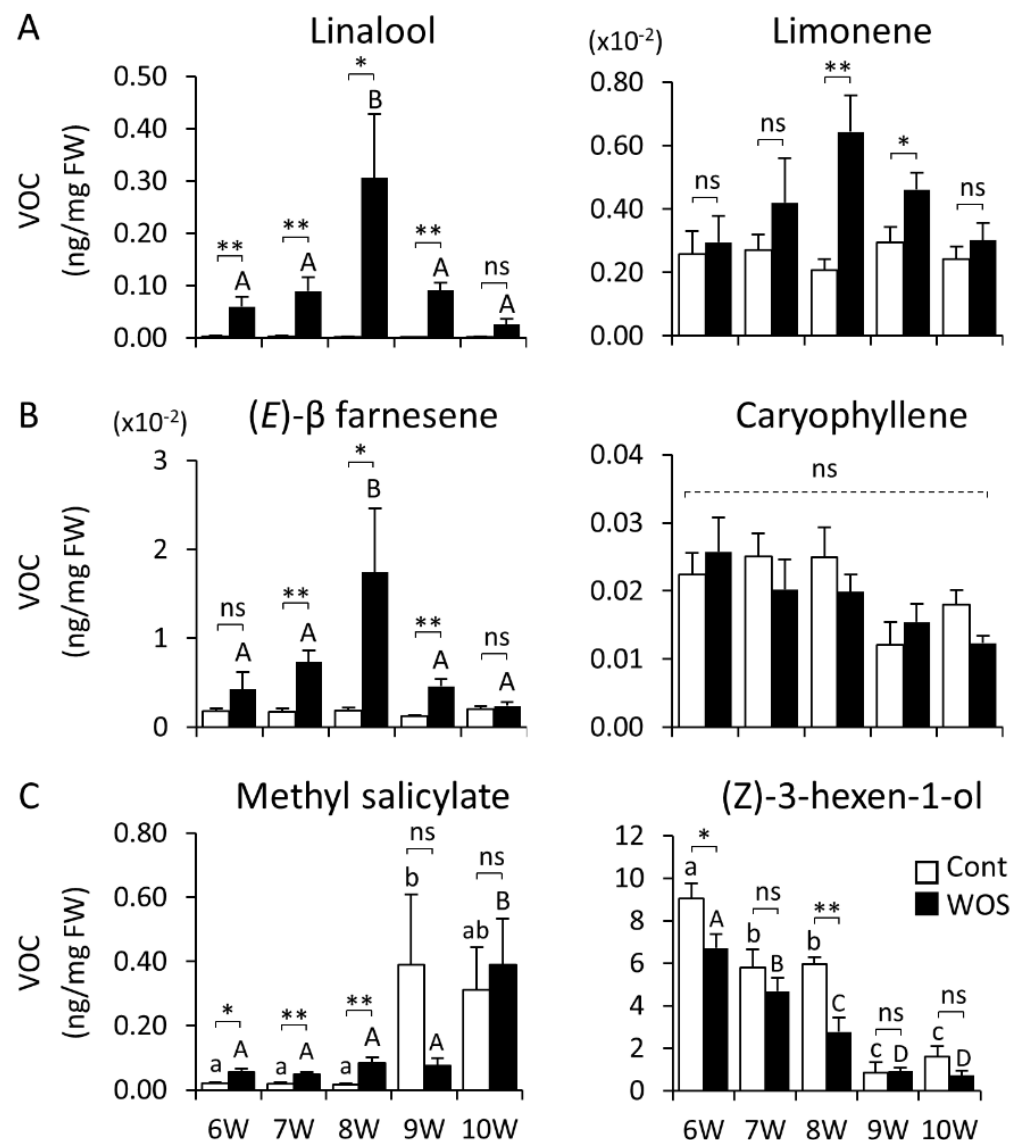

(Z)-3-hexen-1-ol

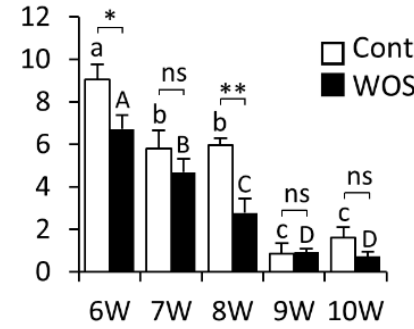

Fig. 1. 
Figure 2
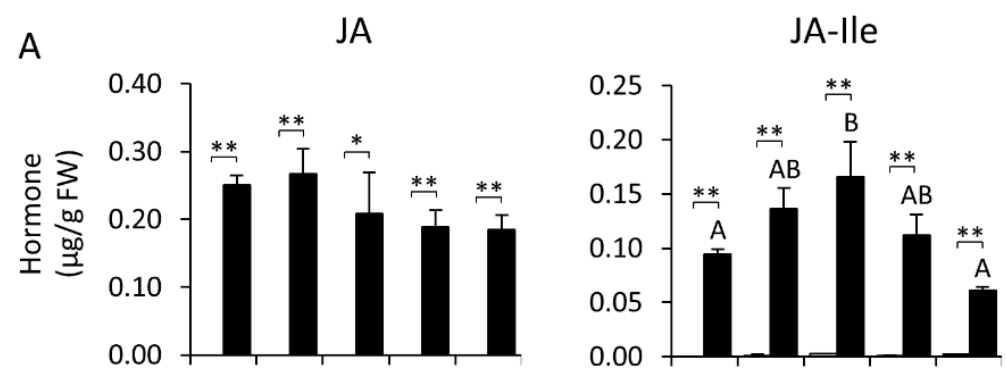

ABA

SA
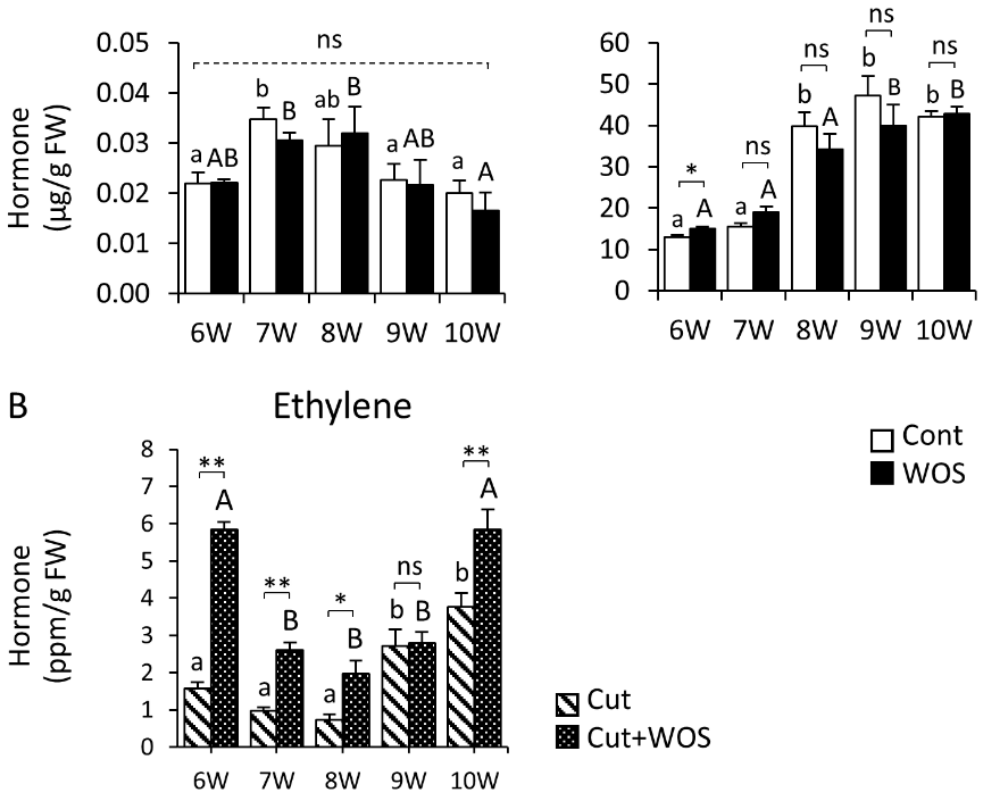

$\square$ Cont

$\square$ wOS

Fig. 2. 
Figure 3

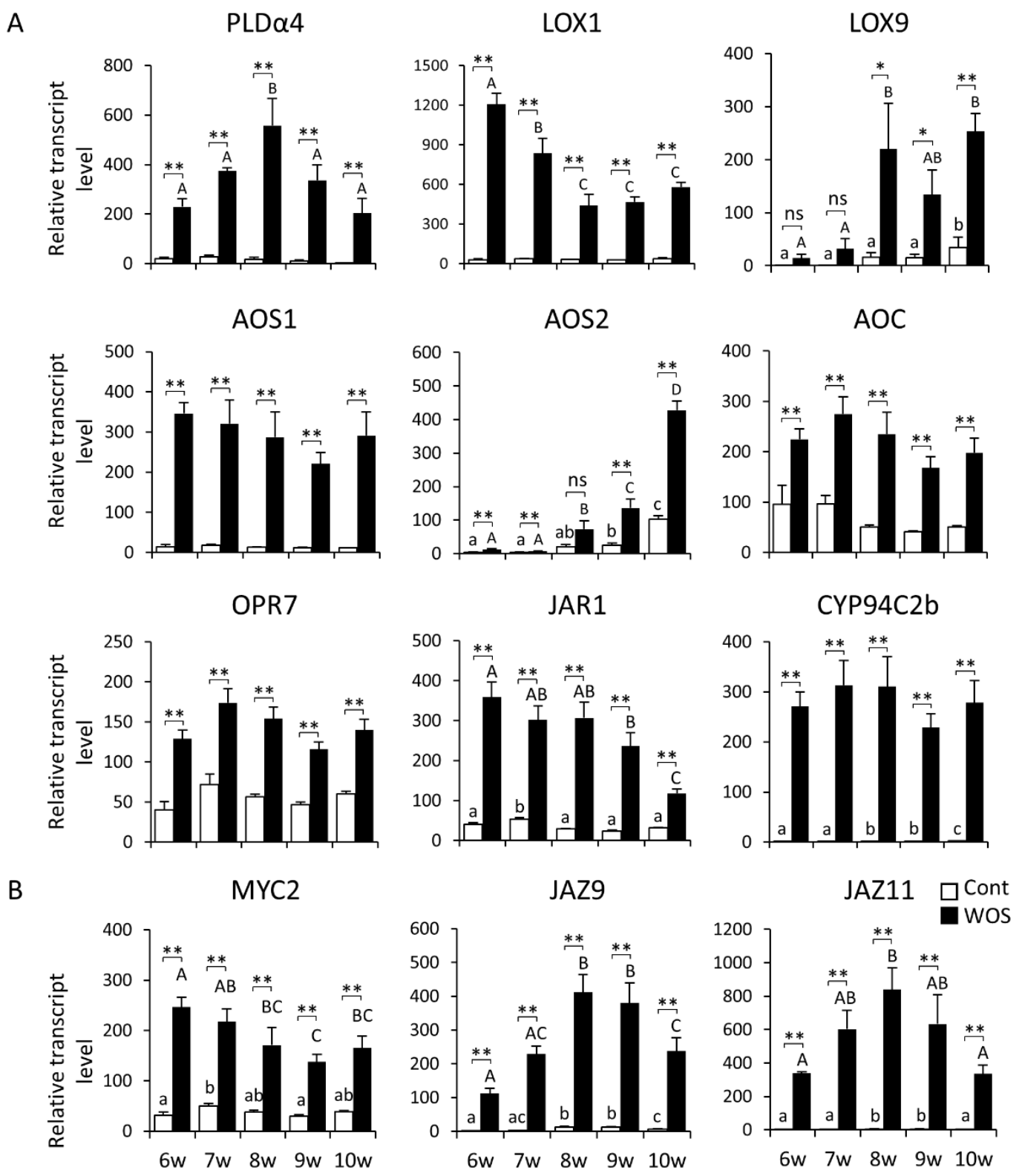

Fig. 3. 
Figure 4

A ACS1

ACS3
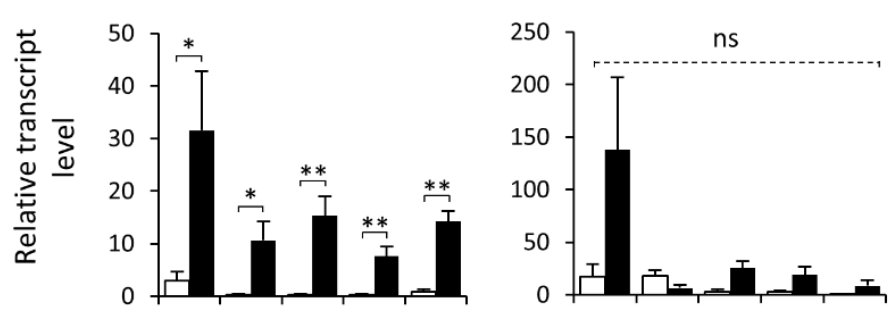

$\square$ Cont

WOS

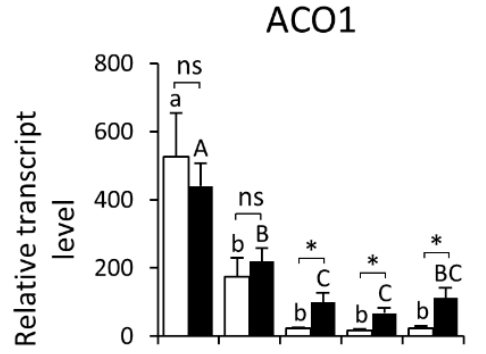

ACO2

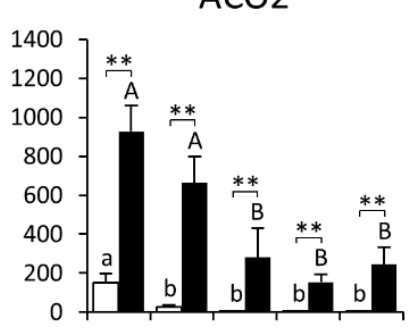

B

ETR2

EBF1

EIL1
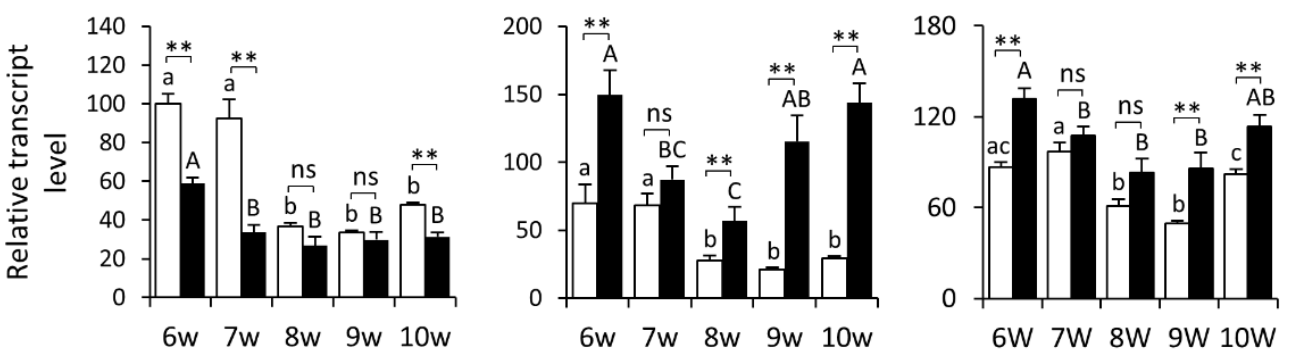

Fig. 4. 
Figure 5

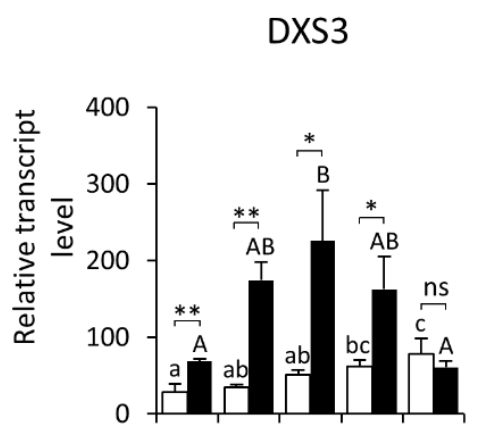

PAL

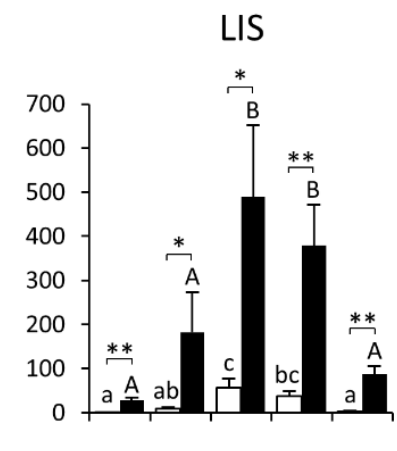

SAMT
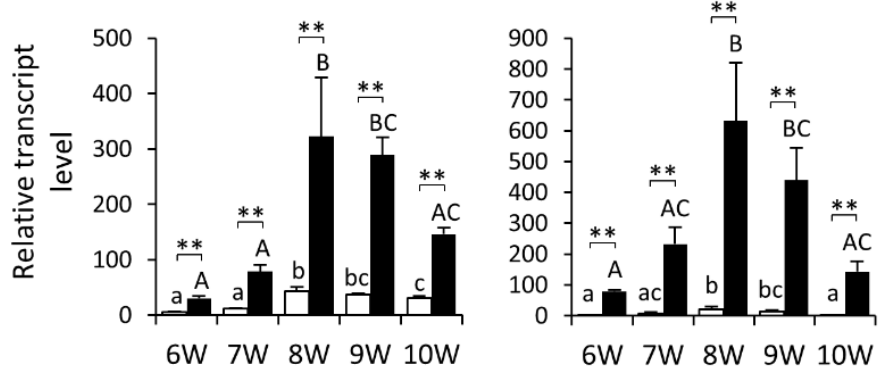

Fig. 5. 
Figure 6
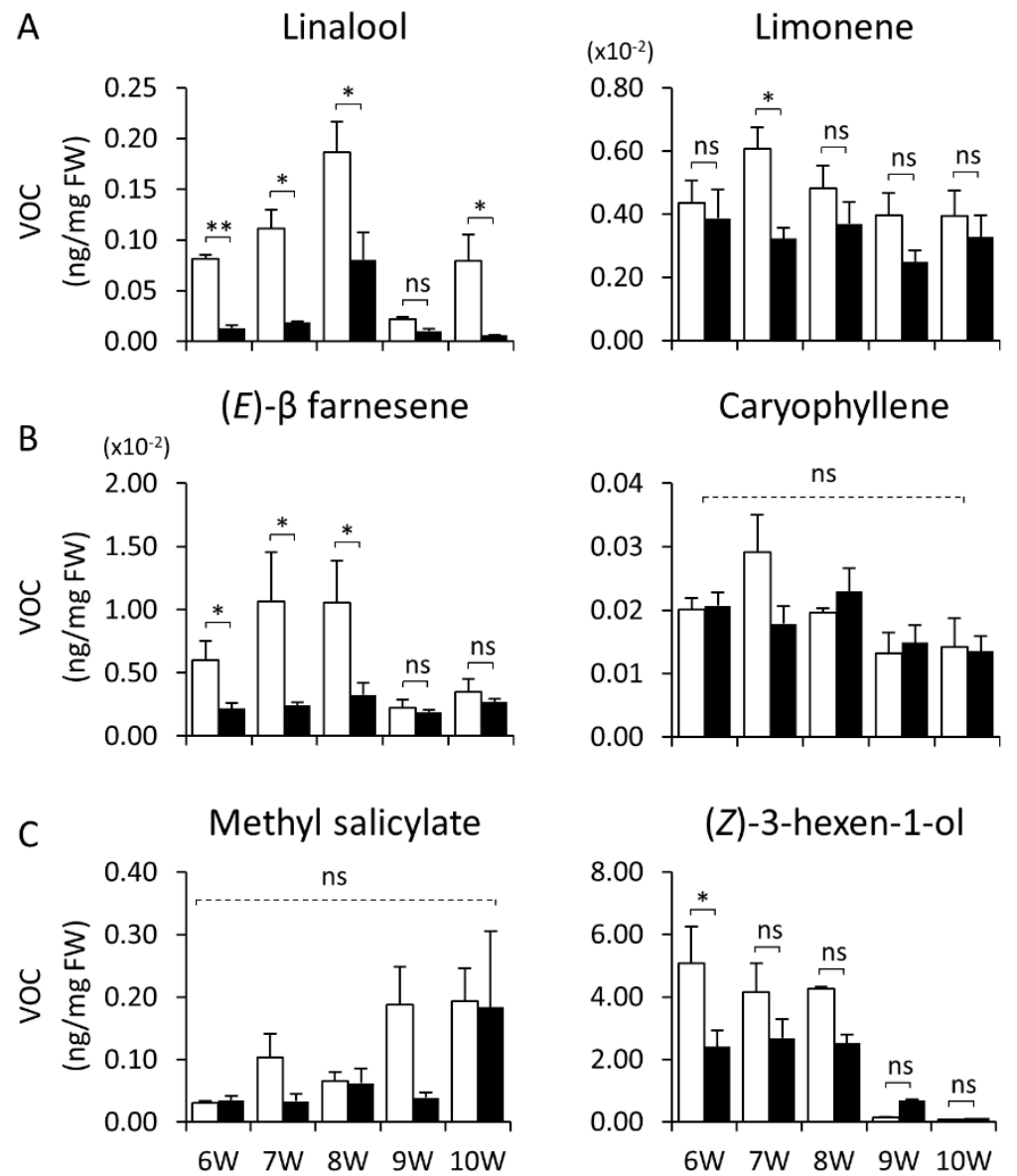

(Z)-3-hexen-1-ol
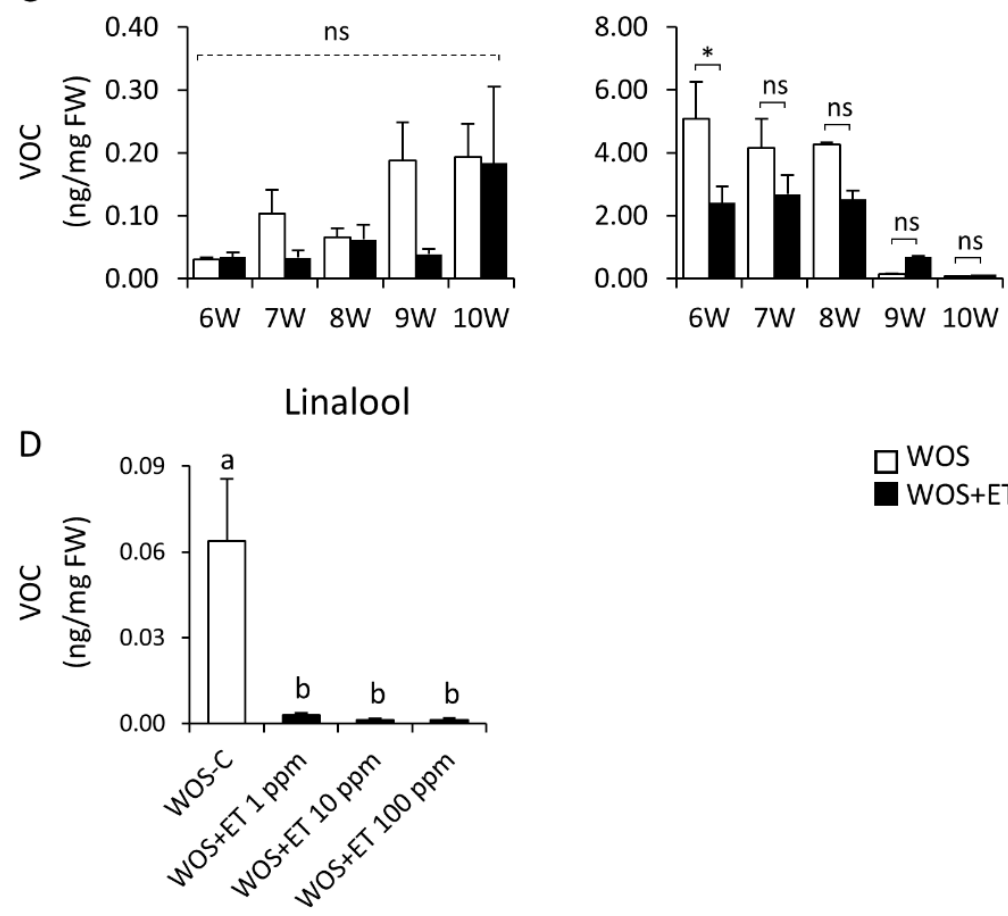

$\square$ WOS

WOS+ET

Fig. 6. 
Figure 7
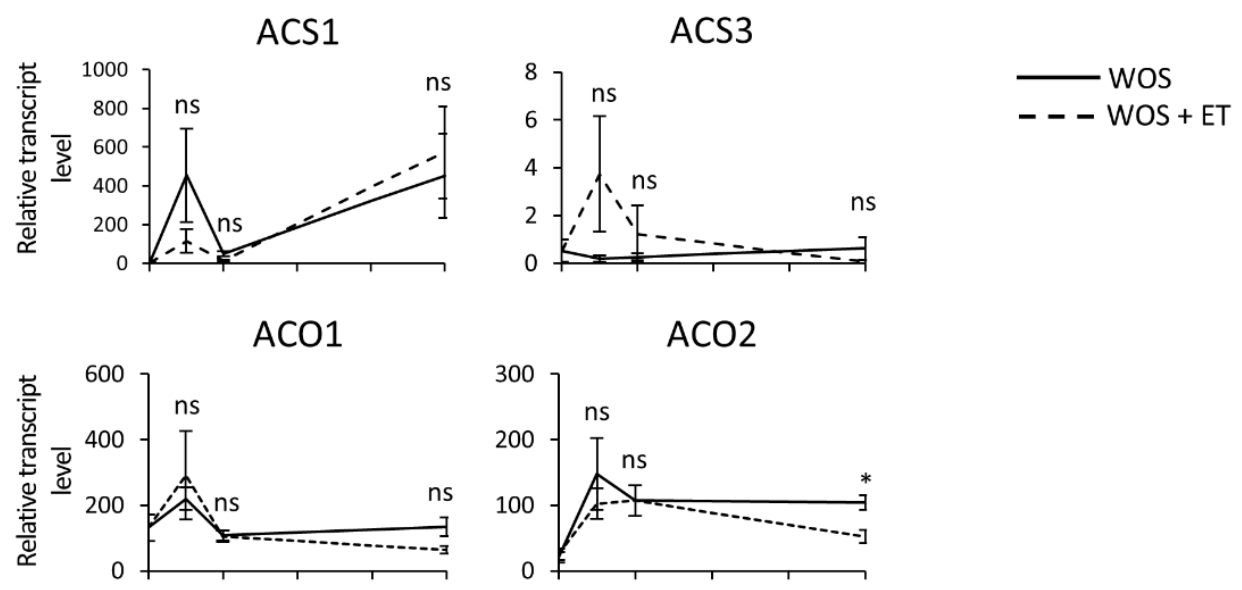

ETR2

EBF1

EIL1
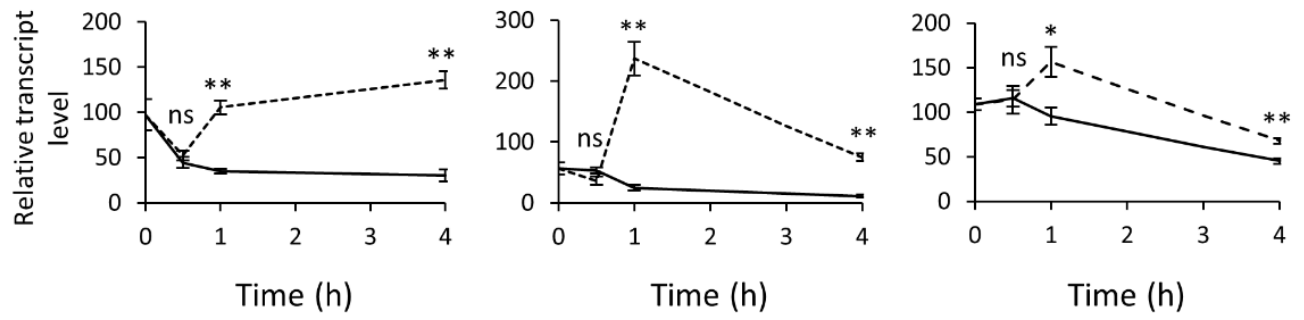

Fig. 7. 
Figure 8
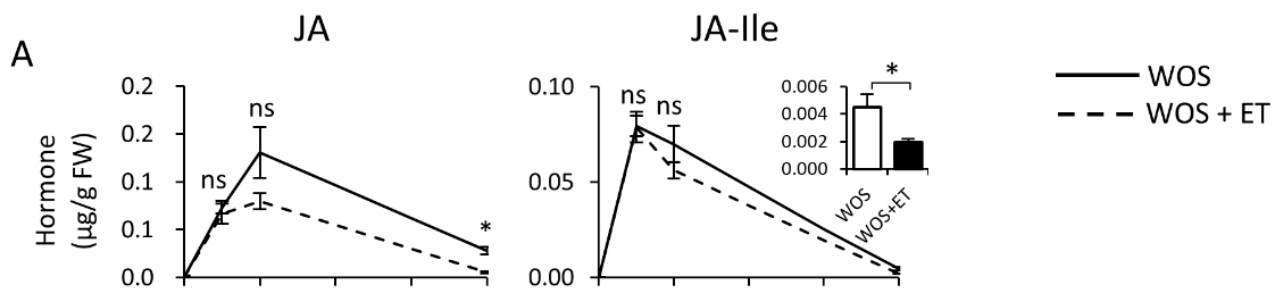

B

PLD $\alpha 4$

LOX1

LOX9
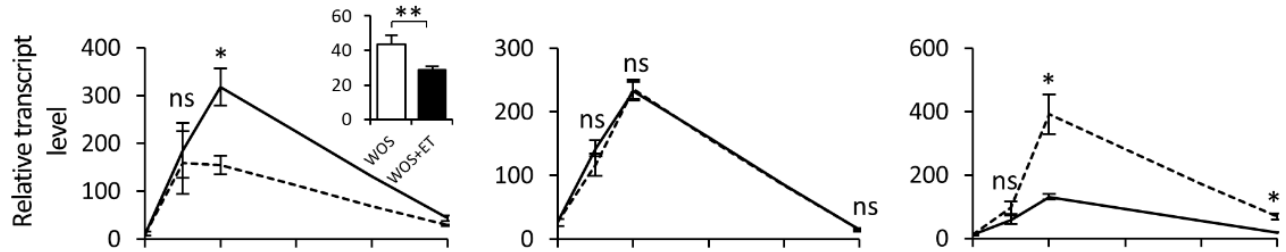

AOS1

AOS2

AOC
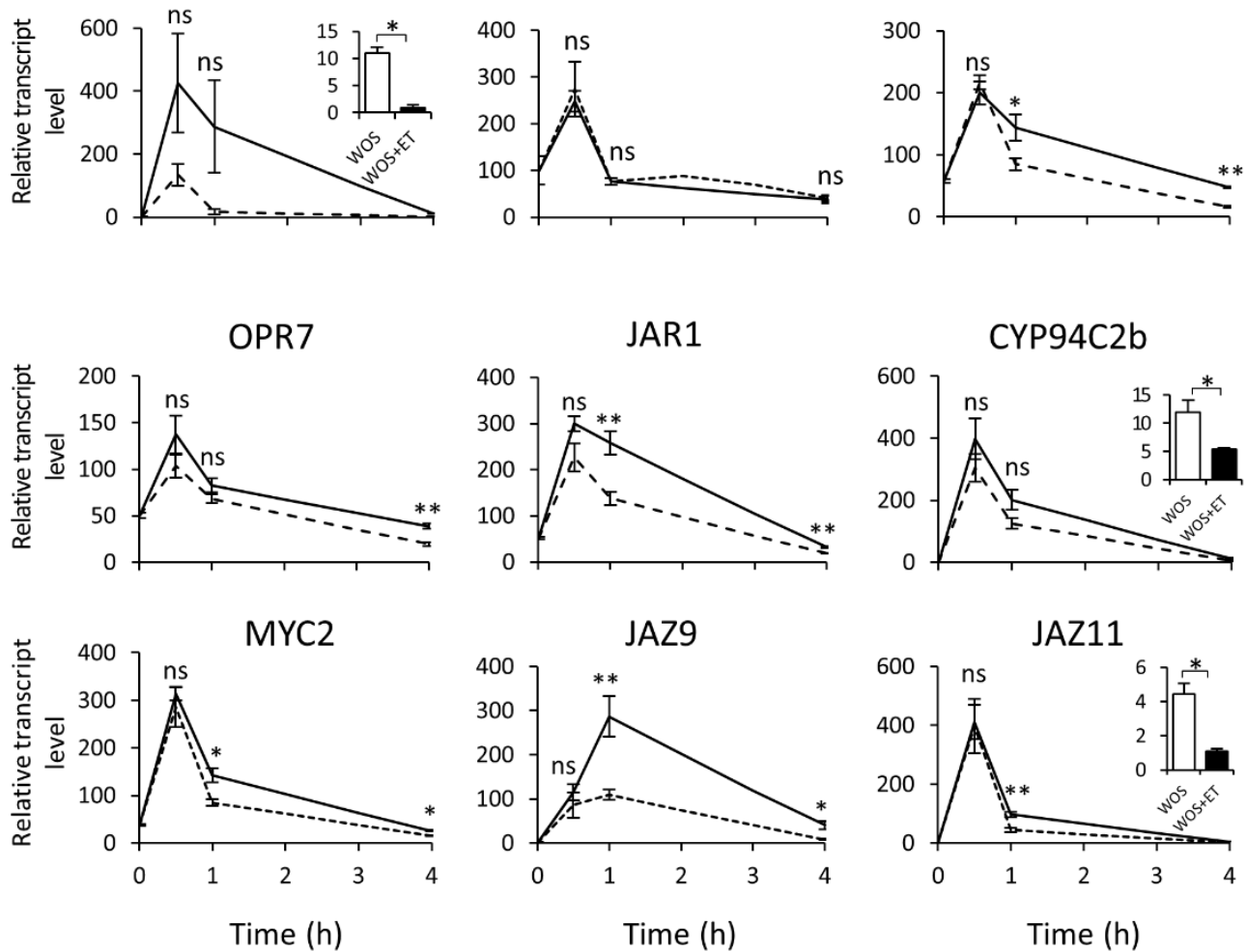

JAZ11

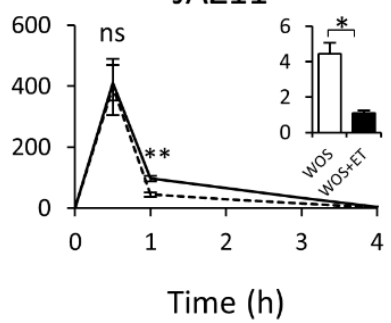

Fig. 8 . 
Figure 9

DXS3

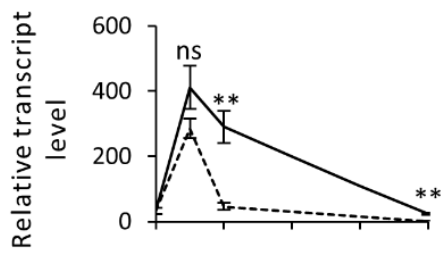

PAL

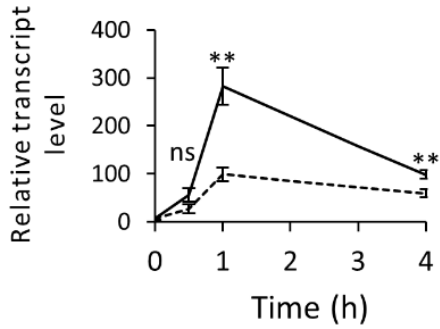

LIS

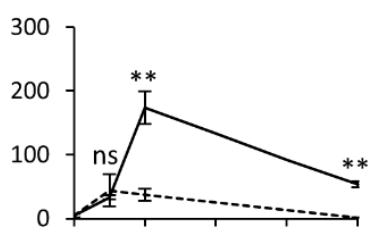

SAMT

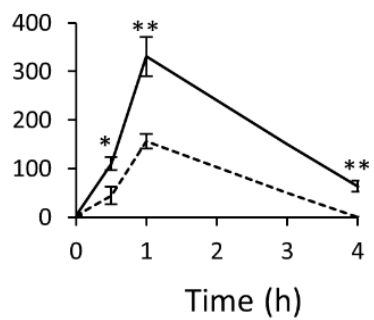

CAS

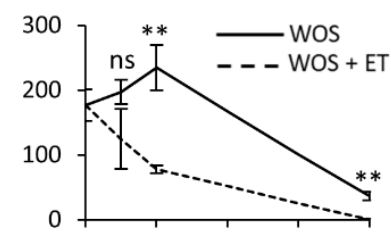

HPL3

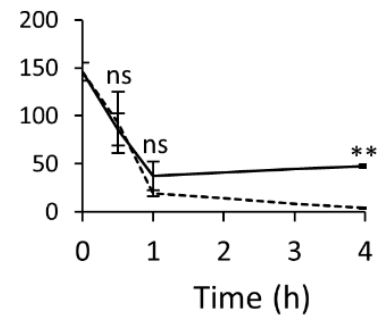

Fig. 9. 
Figure 10

A
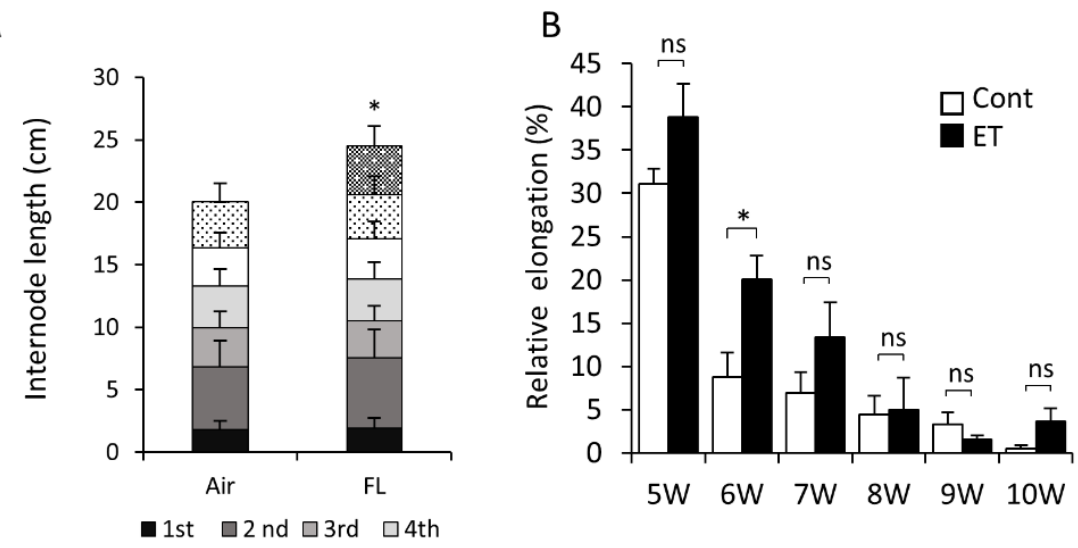

$\square 5$ th . 6 th $\quad$ ith

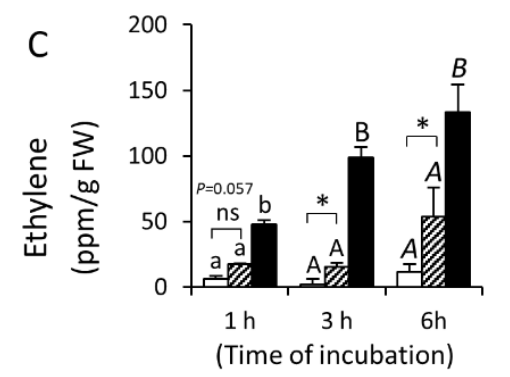

$\square$ Air

$\square \mathrm{FL}$

- FL+WOS

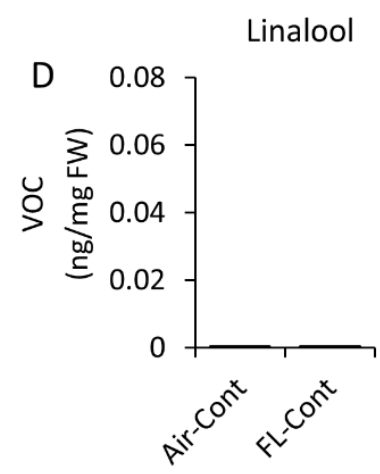

(Z)-3-hexen-1-ol
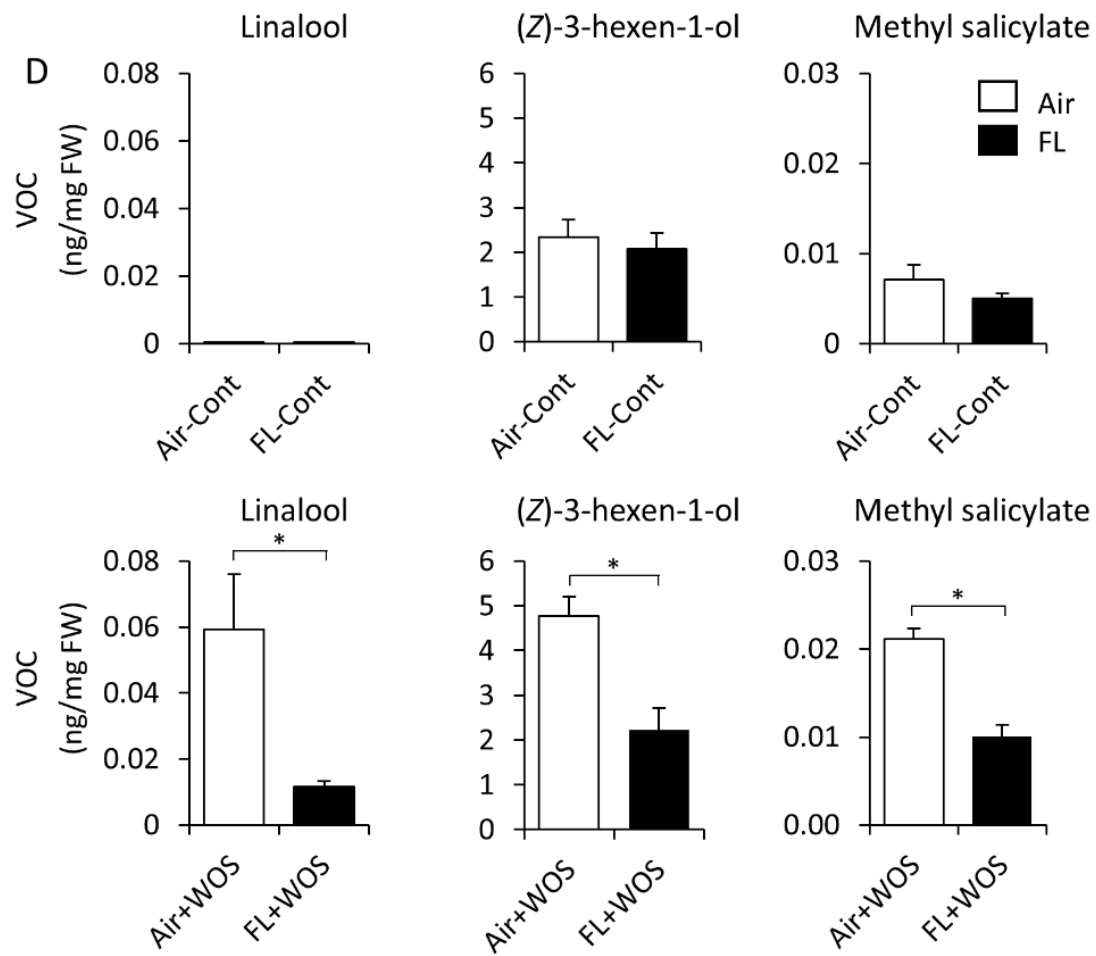

Fig. 10.

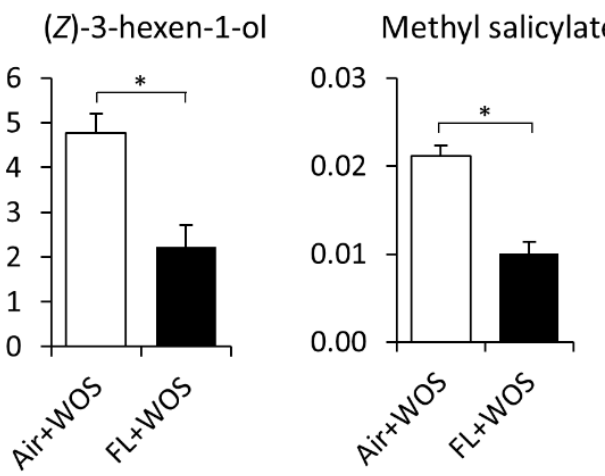


Figure 11
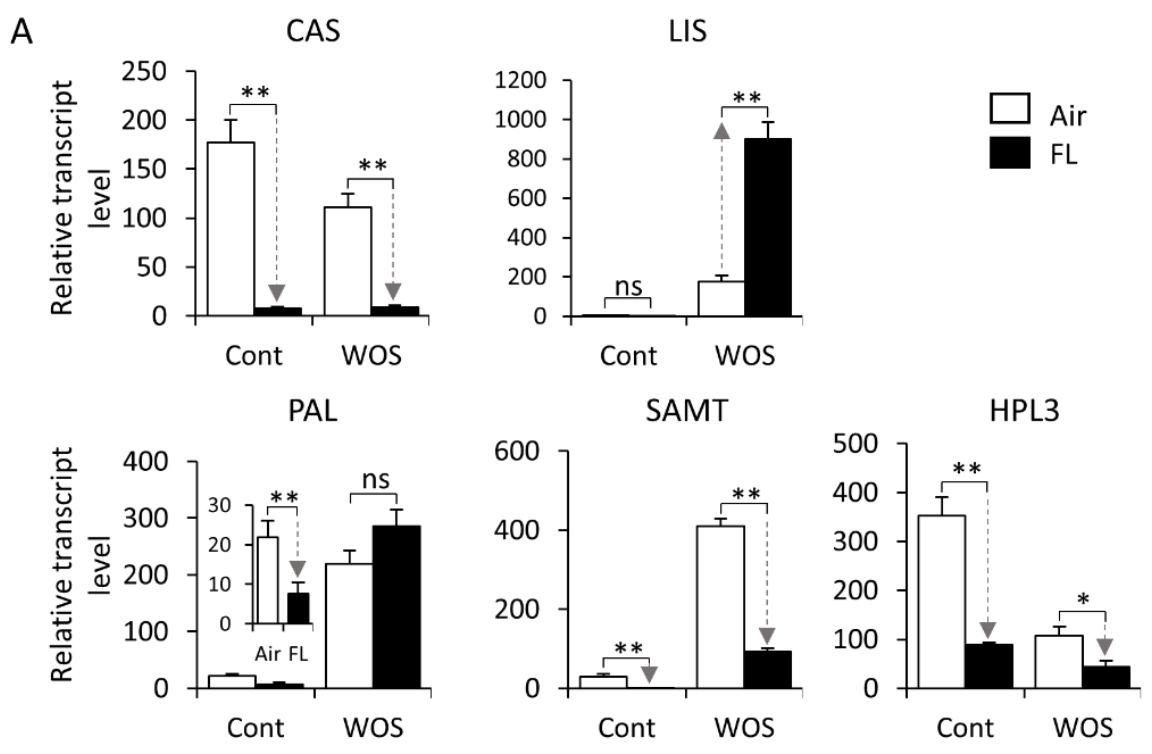

B

JAR1

MYC2
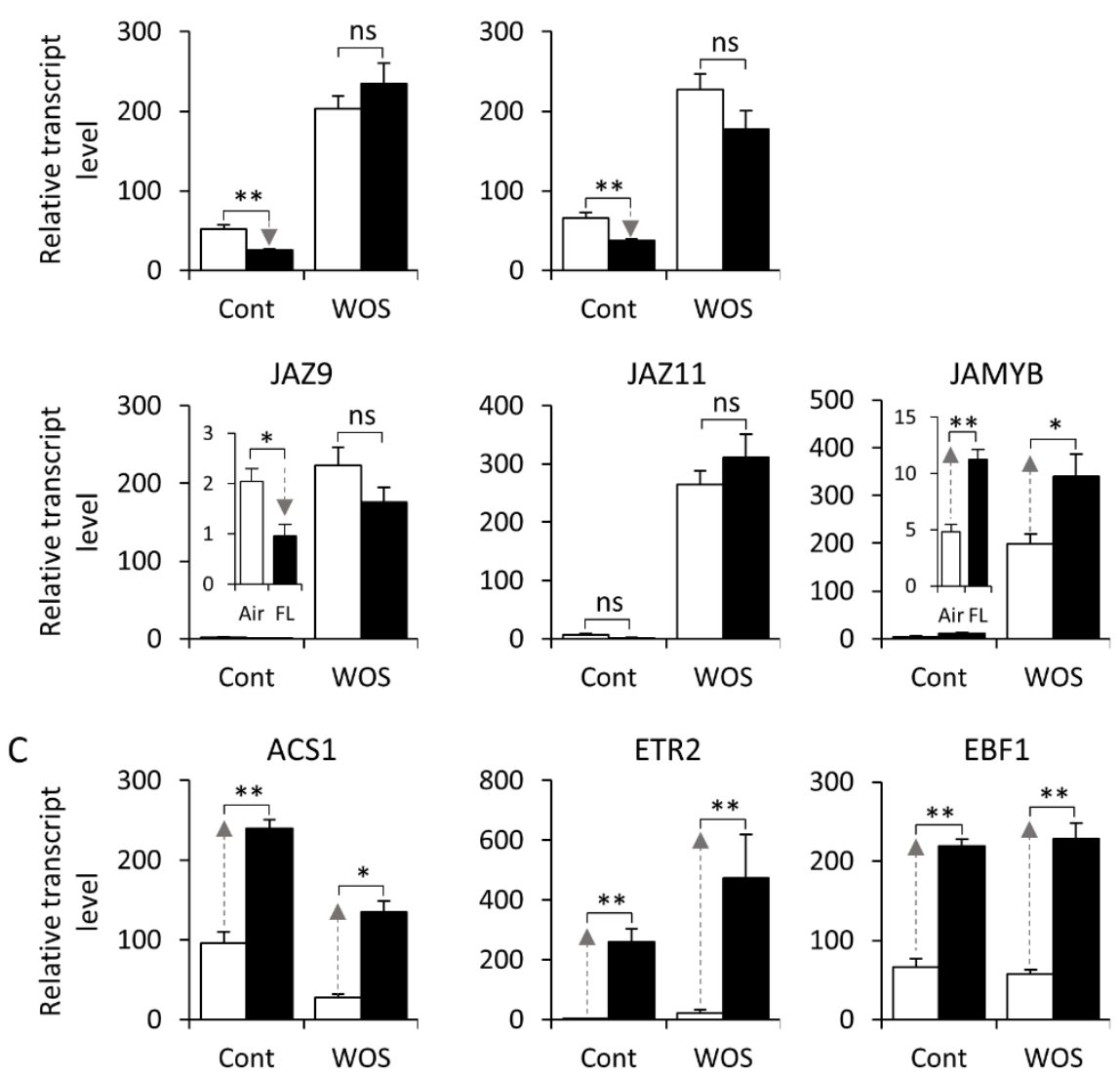

Fig. 11. 
Figure 12
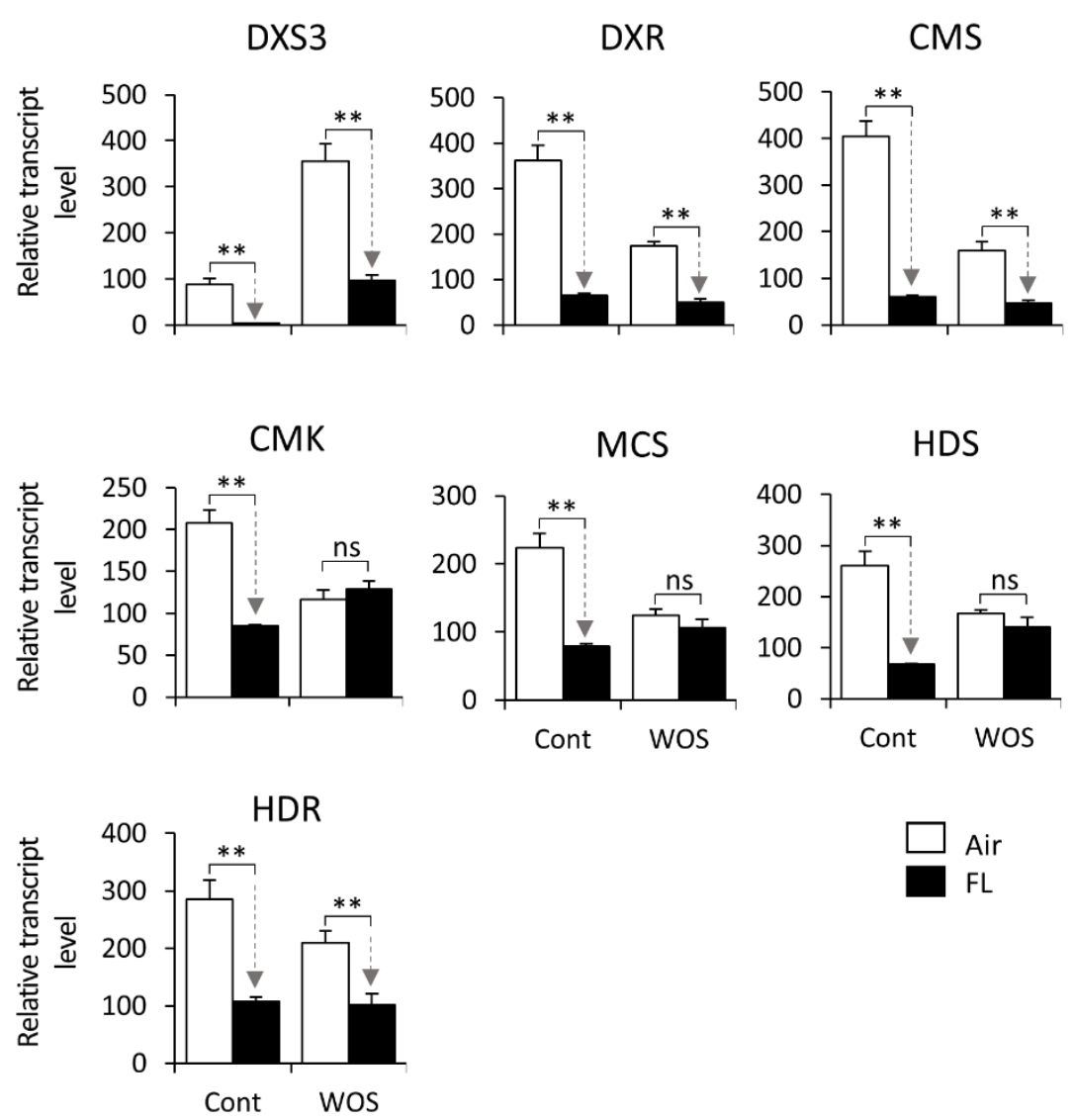

Fig. 12. 
Figure 13
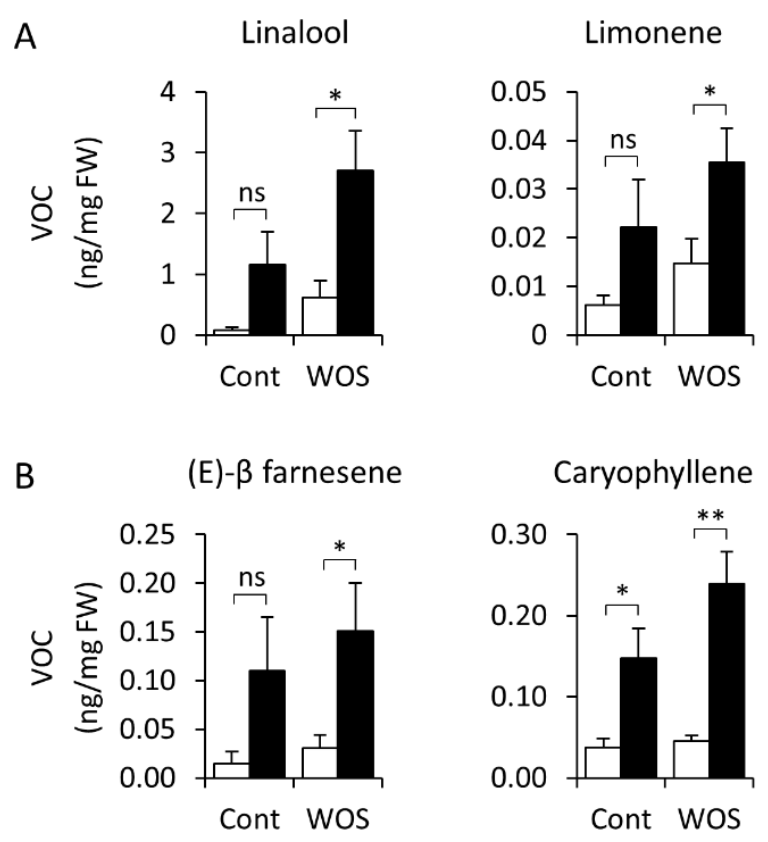

C Methyl salicylate

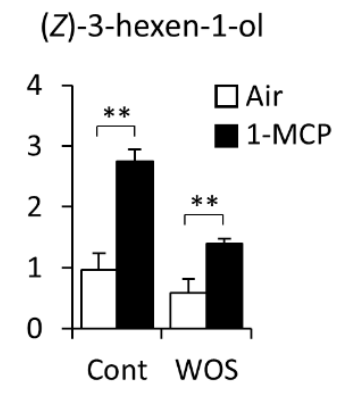

Fig. 13.

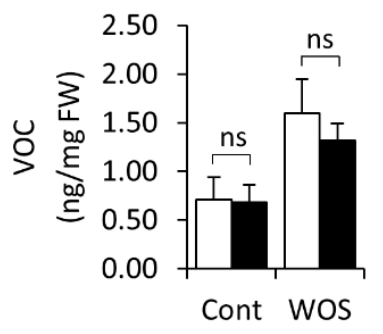


Figure 14
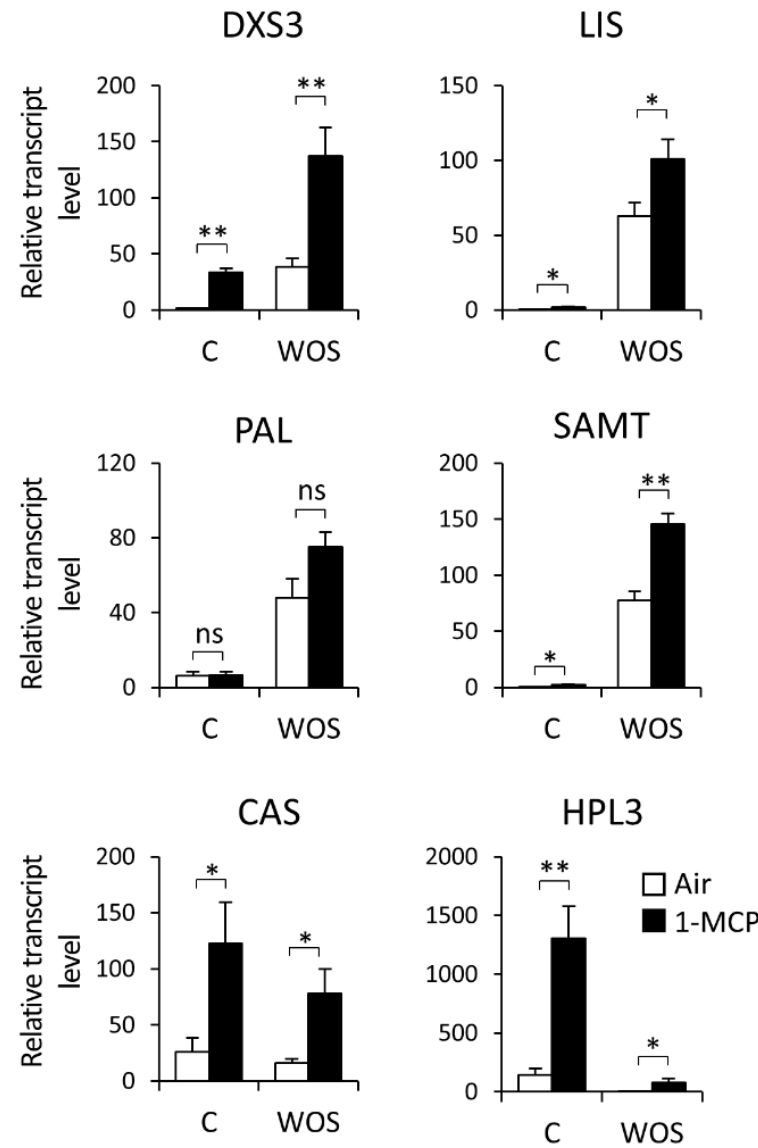

Fig. 14. 